\title{
The Change in the ENSO Teleconnection under a Low Global Warming Scenario and the Uncertainty due to Internal Variability $\mathcal{O}$
}

\author{
Clio Michel AND CAMille Li \\ Geophysical Institute, University of Bergen and Bjerknes Centre for Climate Research, Bergen, Norway \\ ISLA R. SIMPSON \\ Climate and Global Dynamics Laboratory, National Center for Atmospheric Research, Boulder, Colorado \\ INGO BETHKE \\ Geophysical Institute, University of Bergen and Bjerknes Centre for Climate Research, Bergen, Norway \\ MARTIN P. KING AND STEFAN SOBOLOWSKI \\ NORCE Norwegian Research Centre AS and Bjerknes Centre for Climate Research, Bergen, Norway
}

(Manuscript received 27 September 2019, in final form 24 January 2020)

\begin{abstract}
El Niño-Southern Oscillation (ENSO) is a main driver of climate variability worldwide, but the presence of atmospheric internal variability makes accurate assessments of its atmospheric teleconnections a challenge. Here, we use a multimodel large ensemble of simulations to investigate the ENSO teleconnection response to a low global warming scenario that represents Paris Agreement targets. The ensemble comprises five atmospheric general circulation models with two experiments (present-day and $+2^{\circ} \mathrm{C}$ ) in which the same set of ENSO events is prescribed, which allows for quantification of the uncertainty in the ENSO response due to internal variability. In winter, the teleconnection during the positive ENSO phase features a strong negative anomaly in sea level pressure over the northeast Pacific (and vice versa for the negative phase); this anomaly shifts northeastward and strengthens in the warming experiment ensemble. At least 50-75 ENSO events are required to detect a significant shift or strengthening, emphasizing the need to adequately sample the internal variability to isolate the forced response of the ENSO teleconnection under a low warming scenario. Even more events may be needed if one includes other sources of uncertainty not considered in our experimental setup, such as changes in ENSO itself. Over North America, precipitation changes are generally more robust than temperature changes for the regions considered, despite large internal variability, and are shaped primarily by changes in atmospheric circulation. These results suggest that the observational period is likely too short for assessing changes in the ENSO teleconnection under Paris Agreement warming targets.
\end{abstract}

\section{Introduction}

El Niño-Southern Oscillation (ENSO) is a major driver of climate variability on interannual time scales. Anomalous sea surface temperatures (SSTs) in the equatorial Pacific trigger an atmospheric teleconnection, usually described as a wave train from the tropics

Supplemental information related to this paper is available at the Journals Online website: https://doi.org/10.1175/JCLI-D-190730.s1.

Corresponding author: Clio Michel, clio.michel@uib.no to higher latitudes, related to the Pacific-North American teleconnection pattern (Wallace and Gutzler 1981), and extending toward the North Atlantic (Bjerknes 1969; Horel and Wallace 1981). This wave train is characterized by a strong sea level pressure (SLP) anomaly over the northeast Pacific slightly east of the climatological Aleutian low and a North Atlantic Oscillation (NAO)-like signature over the North Atlantic. The ENSO-related changes in atmospheric circulation modify temperature and precipitation globally [Ropelewski and Halpert 1987; Diaz et al. 2001—over North America (Ropelewski and Halpert 1986; L'Heureux et al. 2015; Jong et al. 2016; Fasullo et al. 2018), Europe (Fraedrich 1994; Brönnimann 2007), 
Asia (Huang and Wu 1989), Africa (e.g., Plisnier et al. 2000), South America (e.g., Grimm and Tedeschi 2009), and Australia (e.g., Cai et al. 2011)], although the impacts are not always robust against internal variability especially outside the tropics (Brands 2017). ENSO effects can last for several months, from winter to the following summer (Diaz et al. 2001). These impacts highlight the importance of assessing how ENSO teleconnections will change in the future.

The response of the ENSO teleconnection to global warming is quite varied in modeling studies, both in terms of changes in strength and pattern. Focusing on winter, many studies report a northeastward shift of the North Pacific center of action but they do not agree on the sign of the change in intensity [using coupled models for Meehl and Teng (2007), Müller and Roeckner (2008), Kug et al. (2010), Stevenson et al. (2012), Stevenson (2012), and Zhou et al. (2014); pacemaker experiments for Drouard and Cassou (2019); and uncoupled models for Zhou et al. (2014)]. The shift seems to depend strongly on the period considered and model used. For future warming under the RCP4.5 scenario, 10 out of 19 CMIP5 models exhibit a northeastward shift of the North Pacific center of approximately $0.5^{\circ}-1.5^{\circ} \mathrm{N}$ and $1^{\circ}-11^{\circ} \mathrm{E}$ (Fig. 14.15 in Christensen et al. 2013), but some models produce no shift or even a westward shift, under the RCP4.5 scenario as well as in other warming experimental setups (Schneider et al. 2009; Herceg Bulić et al. 2012; Zhou et al. 2014). No shift and a weakening of the SLP anomaly was obtained by Herceg Bulić et al. (2012) using a model of intermediate complexity; a westward shift along with a strengthening was obtained by Schneider et al. (2009) using uncoupled simulations; and the National Centers for Environmental Prediction-National Center for Atmospheric Research (NCEP-NCAR) reanalysis period 1979-2008 features an intensification and southeastward shift of the El Niño SLP anomaly (Zhou et al. 2014). By using large ensembles of different models the present study will be able to define an uncertainty range in the ENSO response to a warmer atmosphere under the limited warming we would see in the coming decades if Paris Agreement targets are to be met.

Part of the uncertainty in the teleconnection response stems from uncertainty in how ENSO itself will change under global warming. Changes in ENSO amplitude, for example, seem to be closely linked to the mean warming pattern in the tropical Pacific: most models warm more in the eastern tropical Pacific (Zhu and Liu 2009; Collins et al. 2010) and tend to exhibit amplified ENSO variability, but some models warm more in the western tropical Pacific and exhibit reduced ENSO variability (Zheng et al. 2016). In the case of more eastern Pacific warming, the climatological zonal gradient of SST weakens with global warming, leading to a weaker Walker circulation, weaker trade winds, and an eastward shift of the precipitation or convection centers in the equatorial Pacific (Liu et al. 2005; Vecchi et al. 2006; Vecchi and Soden 2007; Müller and Roeckner 2008; Kug et al. 2010; Cai et al. 2015; Drouard and Cassou 2019). The atmospheric ENSO teleconnection tends to follow changes in tropical convection in observations and model simulations for both eastward (Kug et al. 2010; Hoerling et al. 1997) and westward shifts (Schneider et al. 2009). However, experimental setups with more warming in the eastern tropical Pacific can also produce no shift in the North Pacific teleconnection (Herceg Bulić et al. 2012), while uniform SST warming can still produce an eastward shift (Zhou et al. 2014).

In addition to the uncertainty arising from ENSO changes with global warming, there is also uncertainty from internal variability, due to the chaotic nature of the atmospheric and oceanic circulations, that hinders our ability to assess the teleconnection response (Deser et al. 2017; Zheng et al. 2018). As shown in Deser et al. (2017), uncertainty in the observed ENSO teleconnection pattern is large given our current record length covering the twentieth century and is mainly due to atmospheric internal variability rather than to the diversity of the ENSO events themselves. To detect any robust climate signals associated with ENSO, current or future, the internal variability that is unrelated to ENSO has to be accounted for. Thus, large ensembles that sufficiently sample the internal variability are required (Stevenson 2012; Garfinkel et al. 2018). It is still unclear how and if the internal variability changes with global warming (Olonscheck and Notz 2017). The multidecadal variability of ENSO is also a source of uncertainty when estimating ENSO changes in the past, present, and future (Atwood et al. 2017) and is not addressed in the present paper.

Our study aims to quantify the uncertainty from internal variability in the response of the ENSO atmospheric teleconnection to a low global warming scenario (i.e., that which we would experience over the coming decades if the $+2^{\circ} \mathrm{C}$ Paris Agreement target is reached). To this end, we use a multimodel ensemble produced for the Half-a-degree Additional warming, Prognosis and Projected Impacts (HAPPI) project (Mitchell et al. 2017), including five different atmospheric global circulation models (AGCMs) and a very large number of ensemble members (at least 100 per model) compared to previous studies. The HAPPI setup does not allow for an examination of all possible factors that could contribute to changing ENSO teleconnections (e.g., changing ENSO character/flavors or changing ENSO amplitude). In addition, the experimental setup assumes that global warming 
will produce a weaker zonal (east-west) gradient across the tropical Pacific, as predicted by the CMIP5 multimodel mean (Zhu and Liu 2009; Collins et al. 2010) but potentially in disagreement with long-term trends in the twentieth century (L'Heureux et al. 2013; Sohn et al. 2013; Sandeep et al. 2014; Coats and Karnauskas 2017; Johnson et al. 2019; Seager et al. 2019), a discrepancy that must be borne in mind when interpreting the model results.

Given our focus on internal variability, we note that the experimental design is well suited for testing in an idealized setup how the ENSO teleconnection associated with the same set of ENSO events may be altered under a low global warming scenario. In particular, the setup allows us to isolate the magnitude of this change relative to internal variability. The large ensemble of the Community Earth System Model 1 (CESM1) (Kay et al. 2015) is also used to provide a basic comparison between the HAPPI prescribed SST ensembles and a coupled simulation, and insight into the decadal/multidecadal variability of the atmospheric ENSO teleconnection as an additional source of uncertainty.

In section 2, the experimental setup is detailed. Section 3 shows how the ENSO teleconnection in the models compares to ERA-Interim, including an assessment of the ensemble spread. The changes in the atmospheric ENSO teleconnection under a low global warming scenario, their link to tropical deep convection, and the uncertainty due to internal variability are detailed in section 4. Section 5 describes how the changing teleconnection affects North American temperature and precipitation. Finally, we discuss caveats related to the experimental design in section 6 and summarize the results in section 7 .

\section{Data and methods}

Our analysis makes use of the wintertime [DecemberFebruary (DJF)] mean and anomaly of monthly fields. The monthly anomalies are the deviation of the monthly field from the climatological seasonal cycle. Considering each winter month separately gives similar ENSO teleconnection patterns over the North Pacific as using the winter mean in both the present and future experiments (not shown).

\section{a. The HAPPI ensemble}

The HAPPI ensemble ${ }^{1}$ was designed to assess the regional impacts of global warming, accounting for natural variability and model uncertainty in low warming scenarios

\footnotetext{
${ }^{1}$ Data can be downloaded at https://portal.nersc.gov/c20c/ data.html\#DataPortal.
}

(Mitchell et al. 2016, 2017). HAPPI was one of the scientific efforts meant to inform action after the Paris Agreement (UUN-FCCC 2015), which recommended limiting global warming to $+1.5^{\circ} \mathrm{C}$ relative to the preindustrial period. The analysis carried out in this paper uses the present-day and $+2^{\circ} \mathrm{C}$ experiments of five models of the HAPPI ensemble: CAM4-2degree, CanAM4, ECHAM6.3-LR, MIROC5, and NorESM1-Happi [see Table 1 of Li et al. (2018) for details about the models]. For the present-day experiment, the five atmospheric general circulation models were forced with the observed evolution of SST and sea ice from 2006 to 2015 (for NorESM1-Happi, this was extended by 6 months to include the $2015 / 16 \mathrm{El} \mathrm{Niño).} \mathrm{For} \mathrm{the}+2^{\circ} \mathrm{C}$ experiment, weighted averages of the RCP2.6 and 4.5 CMIP5 multimodel mean responses were added to the observed values of SST and sea ice, with the weighting chosen to correspond to a global warming of $+2^{\circ} \mathrm{C}$ relative to the preindustrial period [see Mitchell et al. (2017) for methodology]. Note that the SST and sea ice anomalies (difference between the $+2^{\circ} \mathrm{C}$ and presentday experiments) vary spatially, with more warming in the eastern tropical Pacific than the west (decreasing the east-west SST gradient) and include a seasonal cycle that is identical from year to year (see Fig. $1 \mathrm{~b}$ for the seasonal evolution over DJF 2006/07). Although the models simulate different values of global mean temperature, they produce a consistent answer for the temperature difference between the $+2^{\circ} \mathrm{C}$ and present-day experiments $\left(1.1^{\circ}-1.2^{\circ} \mathrm{C}\right.$ warming, as expected given that the present day is $0.8^{\circ} \mathrm{C}$ warmer than the preindustrial period; Fig. 1a).

\section{b. ERA-Interim reanalysis}

To evaluate the models' performance in reproducing ENSO teleconnections, we compare with monthly sea level pressure data from the European Centre for Medium-Range Weather Forecasts (ECMWF) reanalysis ERA-Interim (Dee et al. 2011) over the same period as the simulations (January 2006-December 2015 for CAM4-2degree, CanAM4, ECHAM6.3-LR and MIROC5; January 2006-June 2016 for NorESM1-Happi), interpolated on a $0.5^{\circ} \times 0.5^{\circ}$ horizontal grid.

\section{c. Large ensemble experiments of the Community Earth System Model}

To complement the analysis and provide insight into the behavior of a coupled model under similar warming levels as HAPPI, we use monthly output from large ensemble experiments of the fully coupled Community Earth System Model 1 (CESM1) (Kay et al. 2015). We use the historical experiment (1920-2005) and the RCP8.5 scenario (2006-2100). In this study, we merge portions 

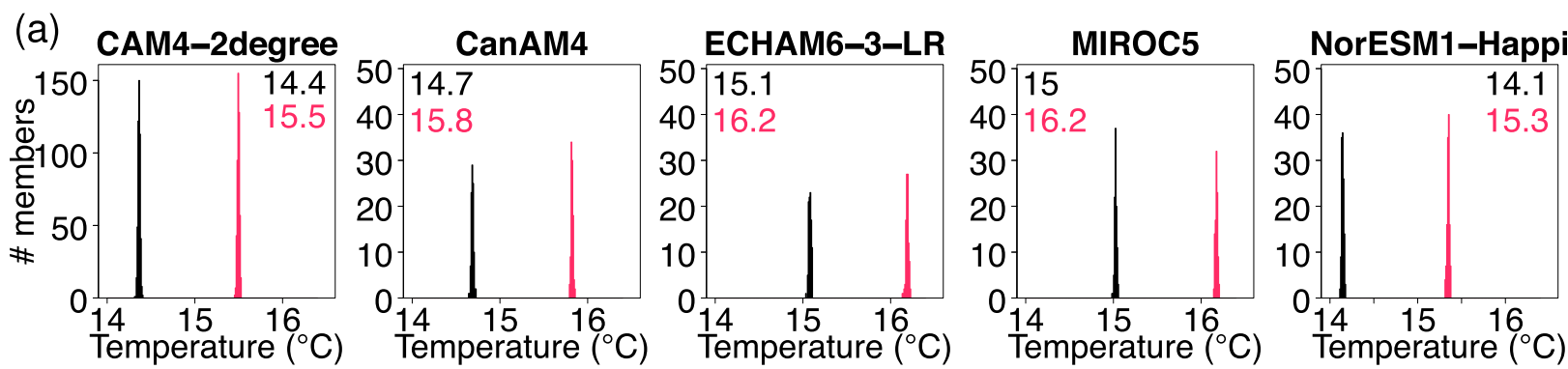

(b)
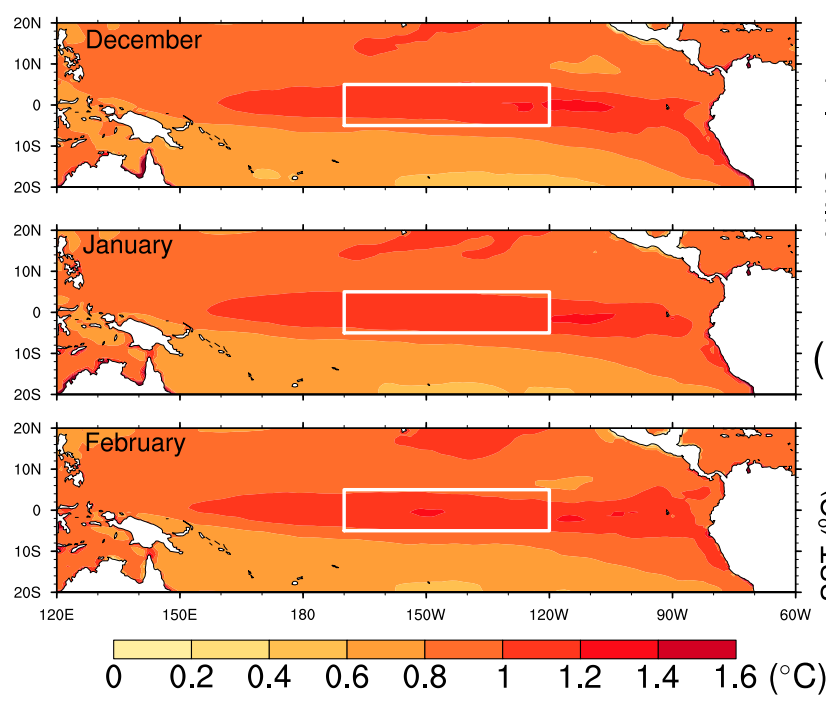

(c)

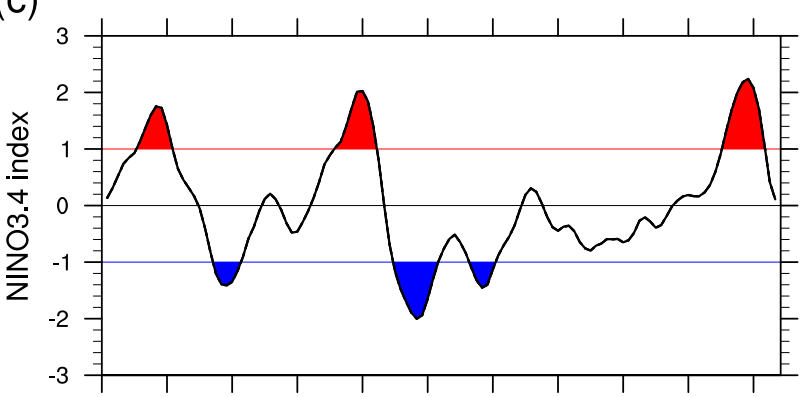

(d)

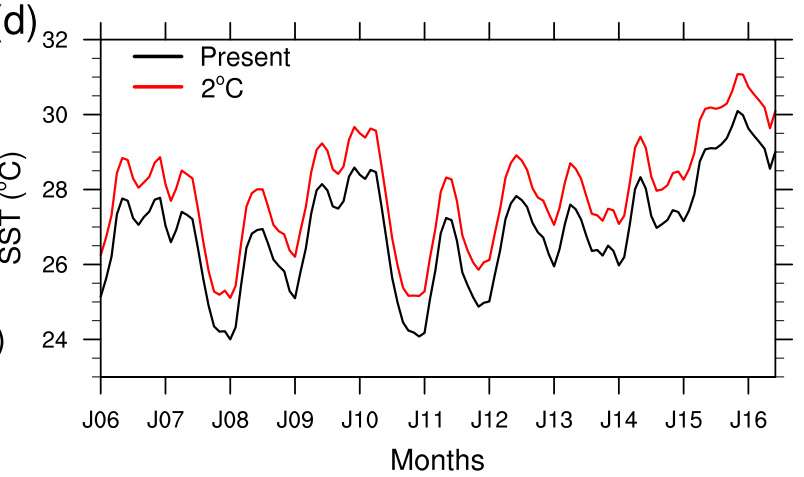

FIG. 1. (a) Distributions of the near-surface air temperature globally and annually averaged from each model for the present-day (black) and $+2^{\circ} \mathrm{C}$ (red) experiments. The values in the top corner of each panel are the means of the distributions. (b) SST difference $\left({ }^{\circ} \mathrm{C}\right)$ between the $+2^{\circ} \mathrm{C}$ and present-day experiments for the winter months. (c) Standardized and detrended Niño-3.4 index. The red (blue) shading shows months with an index above (below) 1. (d) Area-averaged SST $\left({ }^{\circ} \mathrm{C}\right)$ in the Niño-3.4 region for the present-day (black) and $+2^{\circ} \mathrm{C}$ (red) experiments.

of the historical and future periods to produce a 40 member ensemble from 1920 to 2100, which we refer to as CESM8.5 in the rest of the paper.

For comparison with the $+1.2^{\circ} \mathrm{C}$ of warming in the HAPPI $2^{\circ} \mathrm{C}$-present-day response, we focus on two 20 -yr periods, with the first centered on year 2006 (19962015), that is, centered on the first year of the HAPPI simulations, and the second centered around year 2037 (2027-46), corresponding to a $1.2^{\circ} \mathrm{C}$ increase in the ensemble-mean global-mean near-surface air temperature between the two periods. The choice of 20 years is a good compromise between being relatively short (as the HAPPI setup is), yet long enough to sample "enough" ENSO events. CESM8.5 has a similar DJF SST warming from the first period to the second as the warming imposed in HAPPI (see Fig. S1 in the online supplemental material; Zheng et al. 2018).

As in many other CMIP5 coupled models (e.g., Bayr et al. 2019), CESM1 exhibits a cold SST bias in the equatorial Pacific (Zhang et al. 2017) that is thought to degrade the simulated ENSO diversity (Feng et al. 2020).

\section{d. ENSO events}

To define ENSO events, we use the Niño-3.4 index, calculated by area averaging the monthly SST anomalies in the Niño-3.4 region $\left(5^{\circ} \mathrm{N}-5^{\circ} \mathrm{S}, 170^{\circ}-120^{\circ} \mathrm{W}\right)$. We apply a 3-month running average, remove any 10-yr linear trend, and standardize the index by subtracting the 10 -yr mean 
and dividing by the standard deviation (Fig. 1c). El Niño and La Niña events are identified when the index has values above 1 and below -1 , respectively, for the three winter months (DJF). Figure 1c shows that there are six ENSO events: three La Niña events (DJF 2007/08, 2010/11, 2011/12) and three El Niño events (DJF 2006/07, 2009/10, 2015/16) in the NorESM1-Happi simulation; the four other model simulations are missing the 2015/16 El Niño. In the $+2^{\circ} \mathrm{C}$ experiment, the SST warming varies spatially, but the time variability of the Niño-3.4 index and SST averaged in the Niño-3.4 box is identical to the present-day experiments. Therefore, the ENSO events are the same in both experiments, with only the background temperature being $\sim 1^{\circ} \mathrm{C}$ warmer in the Niño-3.4 region in the future experiment (Fig. 1d).

For CESM8.5, we define changes in ENSO teleconnections over the two 20 -yr periods defined above (centered on 2006 and 2037). There are between 4 and 10 ENSO events per period. In addition, we explore changes over continuous 20 -yr periods through the whole 1920-2100 simulation, with a shift of one year (162 periods in total).

Our ENSO composite is the mean anomaly of all El Niño and La Niña events where the La Niña events have been multiplied by -1 , producing one composite for every member of every ensemble. This averages over some nonlinearities between El Niño and La Niña (Hoerling et al. 1997; Herceg Bulić and Branković 2007; Okumura and Deser 2010; Feng et al. 2017; Jiménez-Esteve and Domeisen 2018) but allows us to maximize the sample size of events in the HAPPI 10-yr period. We focus on winter as it is the season during which the Niño-3.4 index peaks and ENSO has its largest impact on the atmosphere, as well as allowing for comparison with many relevant studies (e.g., Hoerling and Ting 1994; Müller and Roeckner 2008; Schneider et al. 2009; Kug et al. 2010; Stevenson et al. 2012; Stevenson 2012; Christensen et al. 2013; Zhou et al. 2014; Cai et al. 2015; Deser et al. 2017, 2018; Jiménez-Esteve and Domeisen 2018, 2019; Drouard and Cassou 2019). The composites are based on a limited number of ENSO events, but this is not expected to substantially affect the results: uncertainty in the ENSO teleconnection arises primarily from internal atmospheric variability rather than ENSO diversity (Deser et al. 2017) and as will be shown below, even with a limited number of events, the canonical ENSO teleconnection is well reproduced. This atmospheric variability is well sampled in the HAPPI "very large" ensemble, which includes a total of 926 realizations all together for each experiment. Thus, despite the various disadvantages of AGCMs (e.g., lack of feedback from atmosphere to ocean, no energy conservation), their use here allows us to run enough realizations to separate the forced signal (e.g., here, changes in ENSO teleconnection due to warming) from the internal variability.

\section{How well is the present-day atmospheric re- sponse to ENSO represented in the models?}

All six models exhibit similar atmospheric ENSO teleconnection patterns in the present-day experiment (Fig. 2). The most prominent feature in winter (DJF) is a negative SLP anomaly over the North Pacific, with variations in magnitude of $1-2 \mathrm{hPa}$ (approximately $25 \%$ ) across models. All models but MIROC5 exhibit a positive anomaly in the Arctic, and all models exhibit a very weak negative anomaly over the North Atlantic (Figs. 2a-c,e,f). The SLP anomaly pattern for each event separately is similar to the full composite (Fig. S2) with the eventto-event difference being comparable to the modelto-model difference. Looking at individual winter months gives similar SLP anomaly patterns that vary in amplitude through the season (not shown).

The simulated ENSO teleconnection compares well to reanalysis data, with some differences in the strength and exact positions of the main centers of action that are common to all HAPPI models (Fig. 3a for CAM4-2degree; other models shown in Fig. S3). The differences reach appreciable amplitudes (e.g., up to $5 \mathrm{hPa}$ for CAM4-2degree over central Eurasia), but there are only limited regions where ERA-Interim lies outside the 5th-95th range of the model ensembles (Fig. S3). Moreover, the spread for ENSO winters is similar to the spread for neutral winters (Figs. 3b,c and Fig. S4), consistent with the idea that atmospheric internal variability shapes the uncertainty in the ENSO teleconnection (Deser et al. 2017) and the year-toyear spread in ENSO's midlatitude impacts (Chen and Kumar 2015). Additionally, we note that the ensemble-mean ENSO teleconnection is similar to the teleconnection derived from observations over the entire twentieth century, a period that includes 18 El Niños and 14 La Niñas (see Fig. 3b in Deser et al. 2017), indicating that despite the limited individual events present in the HAPPI ensembles, they are capable of capturing the canonical ENSO teleconnection.

The North Pacific portion of the ENSO teleconnection exhibits substantial variability across the members in terms of its intensity and location. The spread in the SLP anomaly, that is the difference between the 95th and 5th percentiles of the member distribution, has large values $(8-10 \mathrm{hPa})$ over the North Pacific, a few 
(a) CAM4-2degree

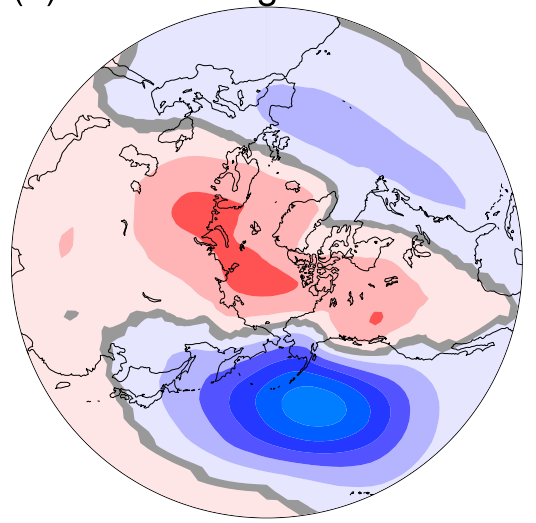

(d) MIROC5

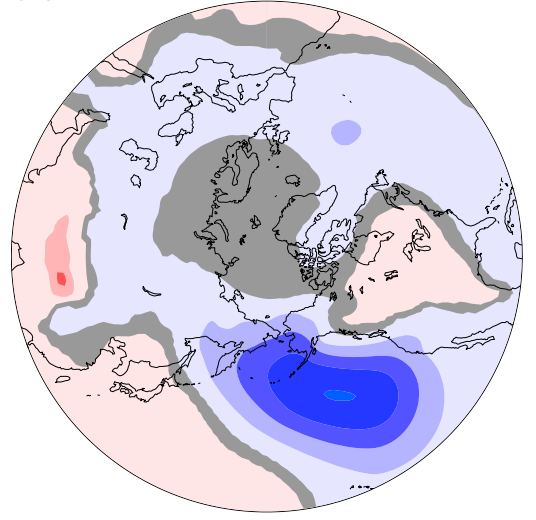

(b) CanAM4

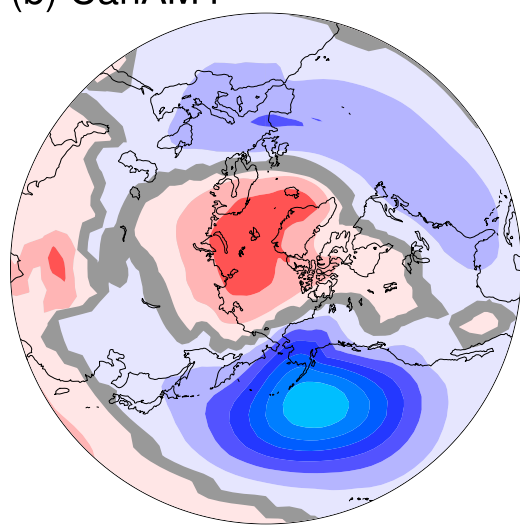

(e) NorESM1-Happi

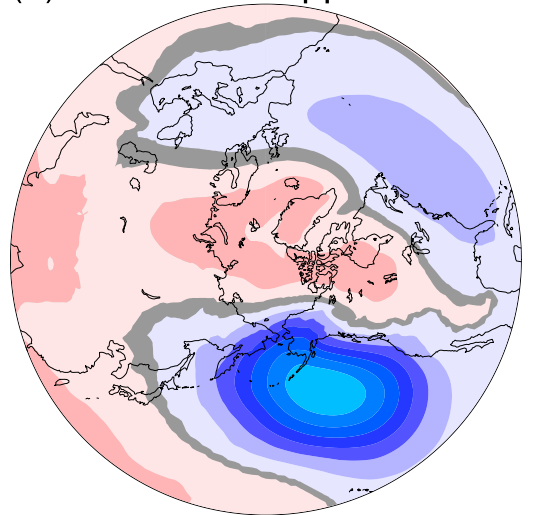

(c) ECHAM6-3-LR

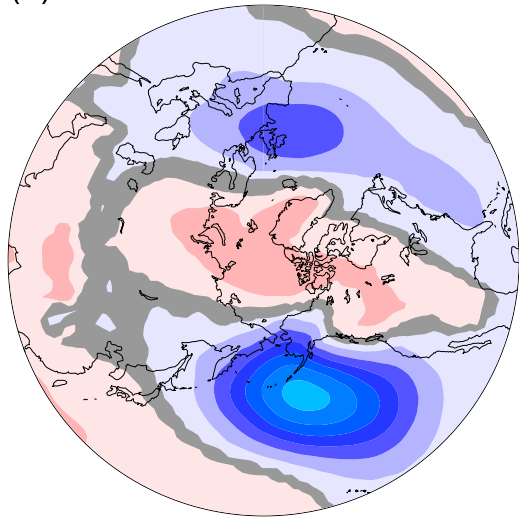

(f) CESM8.5

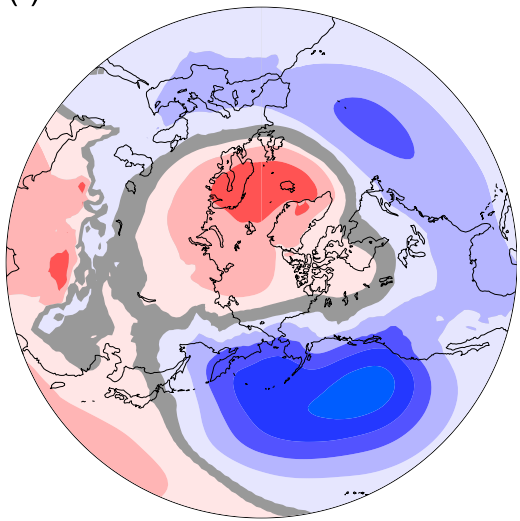

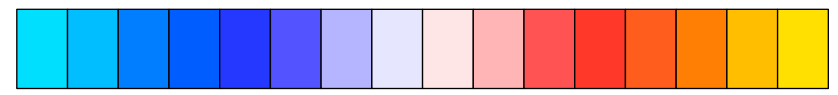

$\begin{array}{lllllllllllllllll}-8 & -7 & -6 & -5 & -4 & -3 & -2 & -1 & 0 & 1 & 2 & 3 & 4 & 5 & 6 & 7 & 8\end{array}(\mathrm{hPa})$

FIG. 2. Ensemble-mean DJF SLP anomaly for ENSO (colored shading) in (a) CAM4-2degree, (b) CanAM4, (c) ECHAM6.3-LR, (d) MIROC5, (e) NorESM1-Happi, and (f) CESM8.5. The gray shading shows areas where the ensemble mean is not significantly different from zero, i.e., areas where the zero value lies within the 5 th-95th percentile range.

degrees poleward of the SLP anomaly center, as well as around the Barents-Kara Seas extending over the North Atlantic (Fig. 3b for CAM4-2degree and Fig. S4 for all HAPPI models).

Figure $3 \mathrm{~d}$ shows the large ensemble spread in the position of the North Pacific SLP anomaly, with the position calculated as follows:

$$
\left\{\begin{array}{c}
\lambda_{C}=\frac{\sum_{\mathscr{D}} \mathrm{SLP}^{\prime 2} \lambda}{\sum_{\mathscr{D}} \mathrm{SLP}^{\prime 2}} \\
\varphi_{C}=\frac{\sum_{\mathscr{D}} \mathrm{SLP}^{\prime 2} \varphi}{\sum_{\mathscr{D}} \mathrm{SLP}^{\prime 2}}
\end{array}\right.
$$

where $\left(\lambda_{C}, \varphi_{C}\right)$ are the longitude and latitude of the "center of action" of the SLP anomaly $\left(\mathrm{SLP}^{\prime}\right)$. The summation is done over all longitudes and latitudes $(\lambda, \varphi)$ in the domain $\mathscr{D}=\left(20^{\circ}-70^{\circ} \mathrm{N}, 120^{\circ}-250^{\circ} \mathrm{E}\right)$, covering a large part of the North Pacific, for which SLP' is negative. On average, the ensemble mean position of the North Pacific center of action is situated south of the Aleutian Islands, but the exact position varies from model to model, e.g., the center in CAM4-2degree is a few degrees southwest of the center in NorESM1-Happi (large filled dots in Fig. 3d). The ERA-Interim center of action (red dot) lies east of the five model-mean centers but well within the spread across individual ensemble members.

Overall, we consider the ENSO teleconnection to be well simulated by the HAPPI models. 
(a) Difference from ERA-I

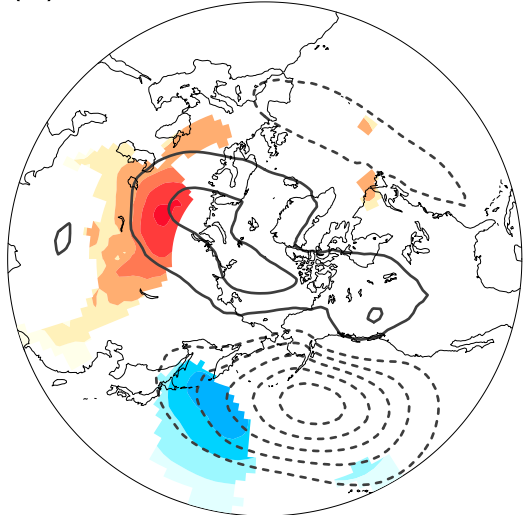

(b) ENSO

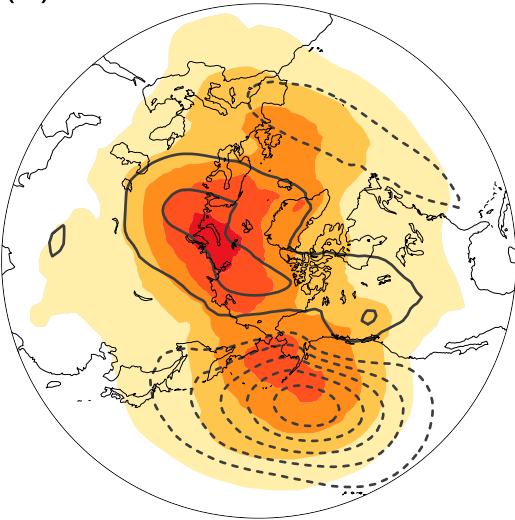

(c) Non-ENSO

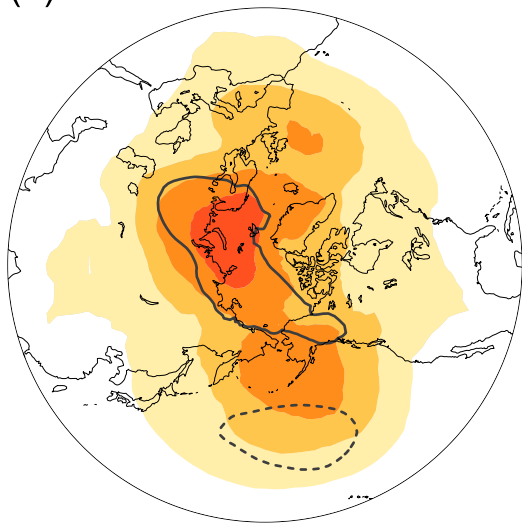

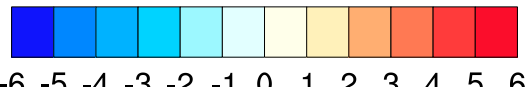

$(\mathrm{hPa})$
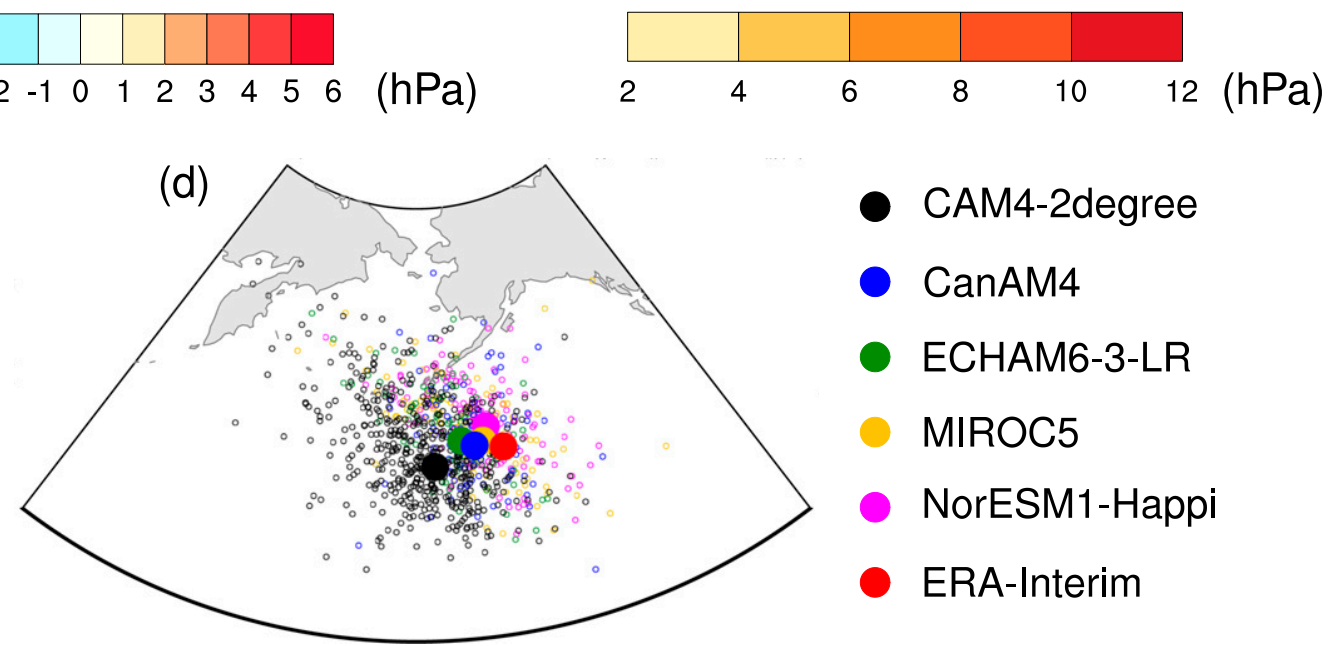

- CAM4-2degree

- CanAM4

- ECHAM6-3-LR

MIROC5

NorESM1-Happi

ERA-Interim

FIG. 3. Simulated ENSO teleconnection in the HAPPI ensemble present-day experiment. (a) Ensemble-mean DJF SLP anomaly for CAM4-2degree (contours; interval: $1 \mathrm{hPa}$; zero contour omitted, negative contours in dashed lines) and its difference from the equivalent ERA-Interim composite (shading; only where the ERA-Interim composite lies outside the 5th-95th percentile range). Ensemble-mean (contours) and 95th-5th percentile spread (shading) in the DJF SLP anomaly during (b) ENSO and (c) non-ENSO winters for CAM42degree. (d) Position of the center of the ENSO DJF SLP anomaly. Small circles show each member. Large dots show the model means. ERA-Interim is represented by the large red dot.

\section{What is the response of the North Pacific ENSO teleconnection to climate change?}

\section{a. Northern Hemisphere response}

In the HAPPI low-warming scenario, the ENSO teleconnection is generally amplified, with some regional differences from model to model (Fig. 4). The most apparent feature of the response pertains to the negative SLP anomaly over the North Pacific, which deepens and/or shifts/extends northeastward (Fig. 4; see section $4 \mathrm{~b}$ for more details). The responses in MIROC5 and CESM8.5 are very weak over the North Pacific compared to the other models.

For some models, there is also a nonsignificant strengthening of the positive Arctic SLP center (over Baffin Bay, Greenland, the Nordic seas, or northwest Russia depending on the model), along with a very weak deepening of the negative SLP center in the North Atlantic. Overall, the signal-to-noise ratio (SNR; the ratio of the ensemble mean to the across-member standard deviation) of the teleconnection response to this low warming scenario is weak, but reaches maximum values of $0.2-0.5$ in parts of the North Pacific (not shown).

Many previous studies have linked ENSO and the NAO, with El Niño favoring the negative phase of the NAO and La Niña the positive phase, subject to some nonlinearities (Fraedrich and Müller 1992; Toniazzo and Scaife 2006; Zhang et al. 2019, and references therein). Figure 4 shows that, for all models except MIROC5, the change in ENSO teleconnection with warming exhibits a weak negative NAO-like response over the North Atlantic region, with negative values 
(a) CAM4-2degree

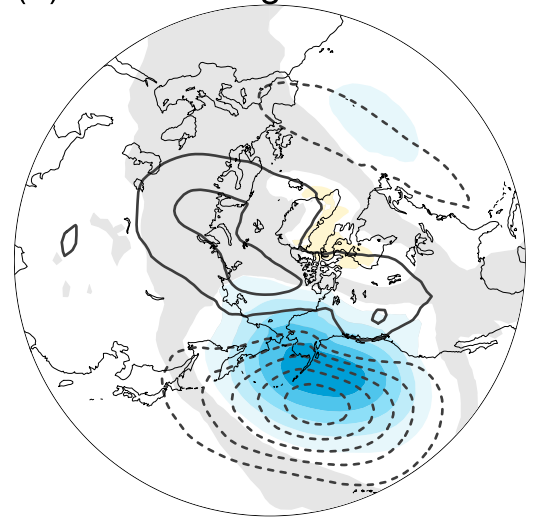

(d) MIROC5

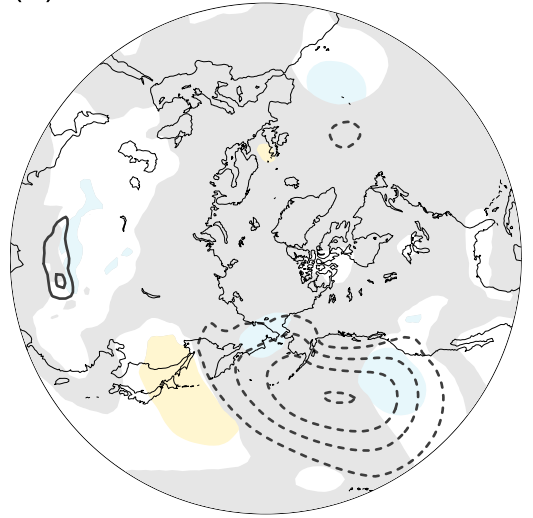

(b) CanAM4

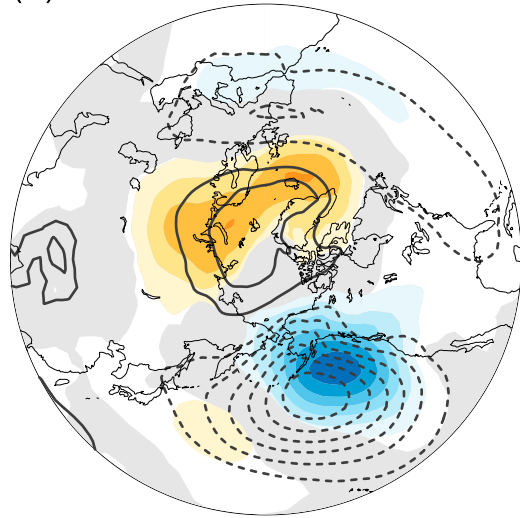

(e) NorESM1-Happi

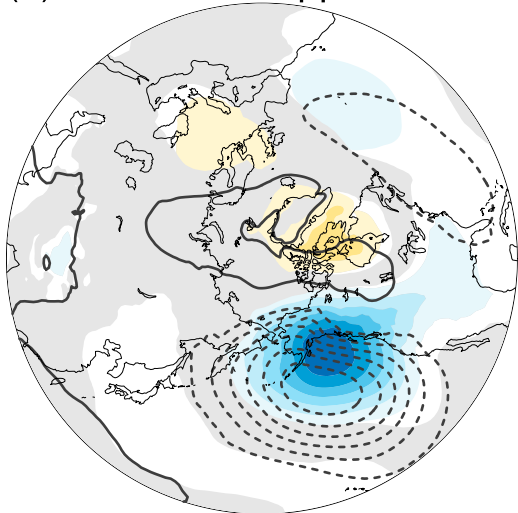

(c) ECHAM6-3-LR

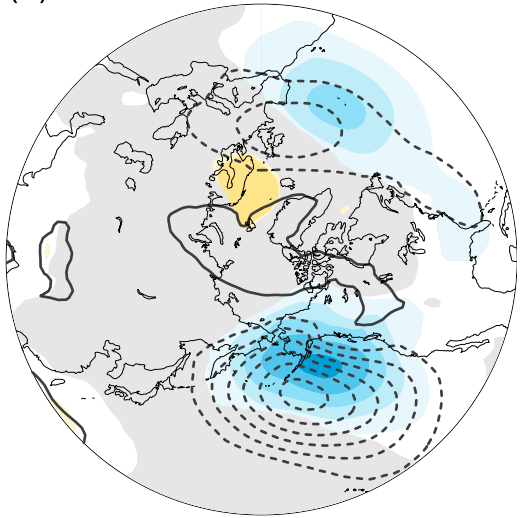

(f) CESM8.5

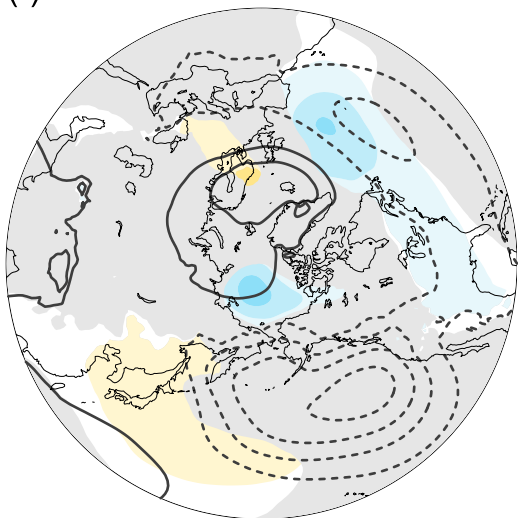

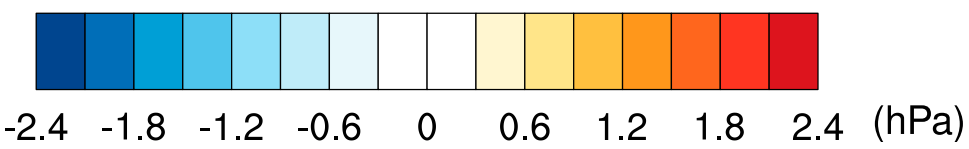

FIG. 4. Ensemble-mean ENSO DJF SLP anomaly for the present-day experiment (contours; interval: $1 \mathrm{hPa}$; zero contour omitted, negative contours in dashed lines) and the $2^{\circ} \mathrm{C}$-present-day response (colored shading) in (a) CAM4-2degree, (b) CanAM4, (c) ECHAM6.3-LR, (d) MIROC5, (e) NorESM1-Happi, and (f) CESM8.5. The gray shading shows areas where the 5th (95th) percentile of a bootstrapped distribution of the ENSO DJF SLP anomaly is positive (negative), that is, areas where the ensemble mean is not significant at the $95 \%$ confidence level.

around the Azores and positive values around Iceland. Similar patterns but with opposite sign are found for El Niño versus La Niña. These very weak responses suggest a possibly stronger link between ENSO and the NAO in the future, as shown by e.g., Müller and Roeckner (2006, 2008). Recently, Drouard and Cassou (2019) pointed to a stronger waveguide between the North Pacific and Atlantic during La Niña episodes as a reason for this stronger link.

\section{b. Focus on the North Pacific}

We now turn our attention to the North Pacific center of the ENSO teleconnection. The northeastward shift with warming can be more precisely evaluated by taking the differences in longitude and latitude of the SLP anomaly center between the $+2^{\circ} \mathrm{C}$ and present-day ensemble means (symbols in Fig. 5a). The uncertainty in the shift is calculated from bootstrapped ensembles created by randomly picking, with replacement, an equivalent number of members to the original ensemble for each model and experiment. We identify the longitude and latitude of the ensemble-mean SLP center within each bootstrapped ensemble and calculate the difference in longitude and latitude between the $+2^{\circ} \mathrm{C}$ and present-day experiments. This operation is repeated 10000 times to create a distribution of position shifts (error bars in Fig. 5a indicating the 5th-95th percentile range of this distribution). While all six models show a 
(a)

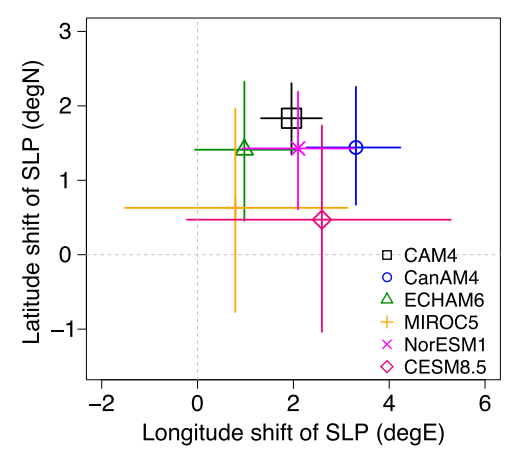

(c)

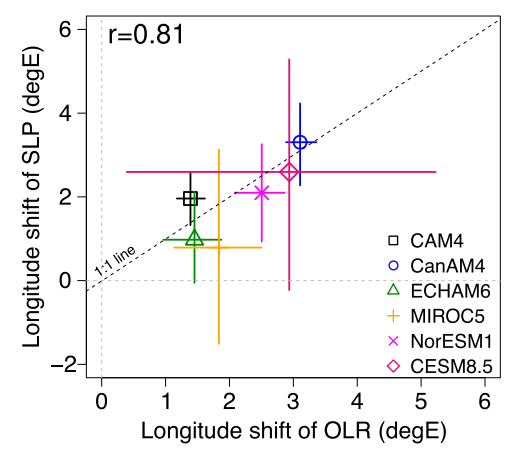

(e)

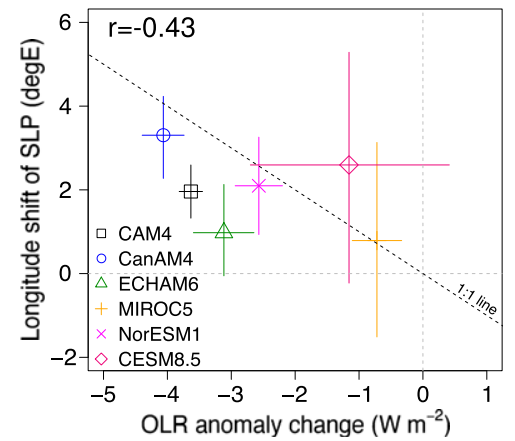

(b)

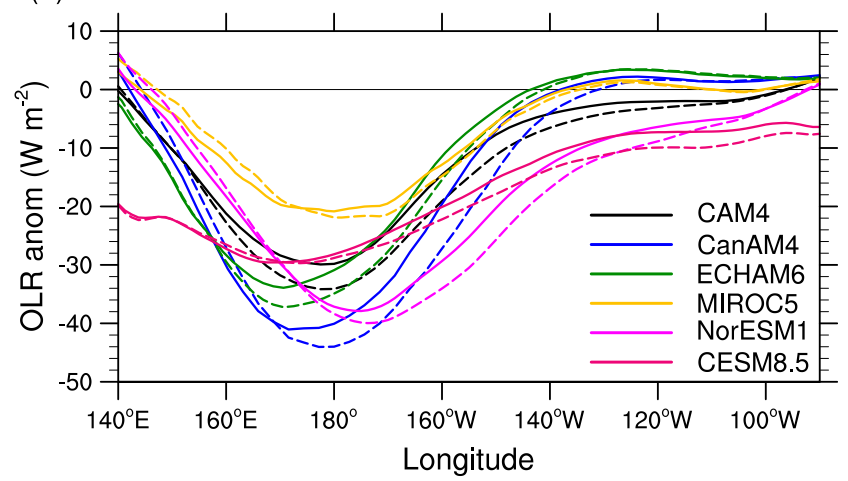

(d)

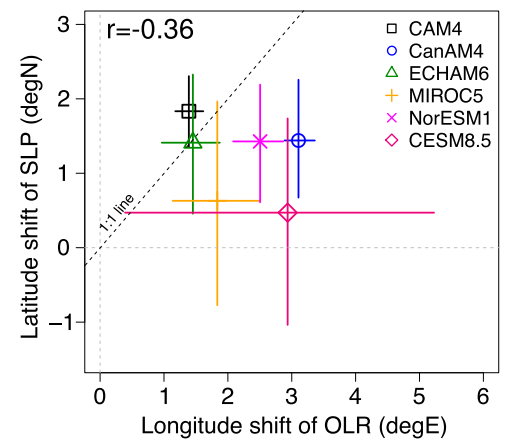

(f)

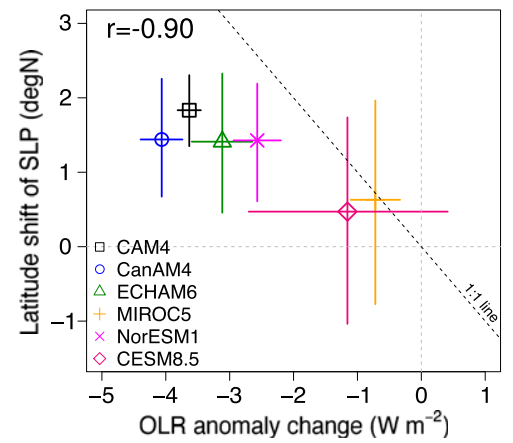

FIG. 5. Ensemble mean and uncertainties on the shift of the North Pacific ENSO teleconnection and link to tropical convection. (a) Shift in latitude vs shift in longitude of the North Pacific center of the DJF SLP anomaly [see Eq. (1) in section 2 for definition]. Symbols show the ensemble mean for each model. (b) ENSO DJF OLR anomaly in the latitudinal band $5^{\circ} \mathrm{S}-5^{\circ} \mathrm{N}$ over the equatorial Pacific (solid line shows the present-day experiment and dashed line shows the $+2^{\circ} \mathrm{C}$ experiment). (c) Shift in longitude of the ensemble-mean North Pacific center vs shift in longitude of the ensemble-mean OLR center. (d) As in (c), but for the latitude of center of the ensemble mean ENSO DJF SLP anomaly. (e),(f) As in (c) and (d), but vs the OLR anomaly change. Crosshairs in (a) and (c)-(f) show the 5th-95th percentile range of the bootstrapped distribution of the shift (details in text). The numbers at the top left of (c)-(f) show the Pearson correlation.

northeastward shift of the ENSO SLP anomaly over the North Pacific, it is only significant for both the longitudinal and latitudinal components (i.e., the 5th percentile is above 0 ) in four of them (Fig. 5a). The ensemble mean of MIROC5 shows a northeastward shift with $+1.2^{\circ} \mathrm{C}$ warming but there is a large uncertainty in this result, with the error bars crossing zero for both longitude and latitude. The uncertainty is also large for the coupled CESM8.5, but this is probably due to the smaller ensemble size ( 40 compared to at least 100 for the HAPPI models). Although a direct comparison of 20 years of CESM8.5 with 10 years of HAPPI is not fully correct due to their different number of ENSO events, taking 40 members of the 125 members of the NorESM1-Happi 
ensemble gives a similar uncertainty as CESM8.5 (not shown).

In agreement with previous studies, the northeastward shift of the North Pacific ENSO teleconnection is at least partly linked to changes in deep convection in the tropics. This deep convection spreads eastward in the $+2^{\circ} \mathrm{C}$ experiment because of more SST warming in the central and eastern tropical Pacific relative to the western tropical Pacific. Figure 5b shows the ENSO OLR anomaly over the tropical Pacific averaged between $5^{\circ} \mathrm{S}$ and $5^{\circ} \mathrm{N}$, with negative values indicating higher/colder cloud tops associated with enhanced convection. The OLR anomaly reaches a minimum between $170^{\circ} \mathrm{E}$ and $170^{\circ} \mathrm{W}$ depending on the model, where the strongest ENSO anomalies in deep convection and therefore precipitation (not shown) occur. Global warming (dashed curves) slightly enhances (more negative OLR) and extends the convection to the east relative to the present-day (solid curves), confirming that the convection can shift eastward even under a weak warming scenario (see also Fig. S5 for a map). Kug et al. (2010) showed a similar eastward shift of tropical precipitation in $\mathrm{CO}_{2}$ doubling experiments. MIROC5 is the model featuring the least negative OLR anomaly and the weakest change with global warming (cf. solid and dashed yellow lines in Fig. 5b). The coupled CESM8.5 exhibits OLR anomalies that extend farther to the west than the HAPPI models but have a similar (though weaker) response to global warming.

Both the position and intensity of the OLR anomaly can influence the teleconnection. To determine the position of the OLR anomaly, we apply Eq. (1) to the OLR in the tropical Pacific domain $10^{\circ} \mathrm{S}-10^{\circ} \mathrm{N}, 150^{\circ}-260^{\circ} \mathrm{E}$. The shifts in longitude of the OLR and SLP anomalies are almost linearly related: the larger the longitude shift in the OLR anomaly, the larger the longitude shift in the SLP anomaly (Fig. 5c). The relationship between the latitude shift of the SLP anomaly and the longitude shift of the OLR anomaly is not as clear as for the longitude shift of the SLP anomaly (Fig. 5d) [Note that the OLR anomaly does not shift in latitude (not shown).] The change in strength of the OLR anomaly with warming (averaged in the region $5^{\circ} \mathrm{S}-5^{\circ} \mathrm{N}, 160^{\circ}-220^{\circ} \mathrm{E}$, where the response is the largest) is plotted against the longitude and latitude shift of the SLP anomaly in Figs. 5e and 5f. These panels show that larger OLR anomalies in the region are also associated with a greater eastward and northward shift of the SLP anomaly.

The response of the ENSO teleconnection to global warming seems closely linked to the response of the mean state (Herceg Bulić et al. 2012). In the HAPPI setup, the mean SSTs warm more in the eastern equatorial Pacific than the western equatorial Pacific (as for CESM8.5; see
Fig. S1), favoring an eastward shift in convection that in turn affects atmospheric variability modes such as the Pacific-North American pattern. For the HAPPI models, the wintertime mean state has the same response to global warming as the ENSO teleconnection, with a strengthening and extension of the Aleutian low toward the east, whereas there is not much change for CESM8.5 over the North Pacific (see Fig. S6). This change in the HAPPI models is associated with a strengthening of the zonal wind around $30^{\circ} \mathrm{N}$ in the eastern North Pacific and an eastward displacement of the stationary waves in the northeastern North Pacific (see Figs. 5 and 10 of Li et al. 2018).

\section{c. How many members are required to detect a significant change with global warming?}

The purpose of using a large ensemble is to be able to separate the forced climate change signal from the internal variability. One may wonder how many members the ensemble must contain in order to detect a significant response to the forcing. Or equivalently, what is the minimum number of ENSO events that is required to detect a robust change in the near term under Paris Agreement targets? To answer this question, we create bootstrapped distributions of the ENSO teleconnection response for ensembles containing a given number of members. The response metrics of interest are the strength and position of the SLP center in the North Pacific. For example, to assess the uncertainty using one-member ensembles, we randomly pick one member each from the $+2^{\circ} \mathrm{C}$ and present-day experiments, calculate the desired SLP metrics, take the difference between the two experiments, and repeat this operation 10000 times. For the uncertainty using two-member ensembles, we pick two members from each experiment and repeat the procedure, and so on for ensemble sizes up to the maximum number of members for the model considered. When more than one member is used, the ensemble mean is calculated before calculating the SLP metrics. We determine the anomalies to be significant when the 5 th-95th percentile range does not encompass zero.

When using all members, every model shows a deepening of the ENSO teleconnection in the SLP anomaly over the northeast Pacific. The strength of the teleconnection is calculated by averaging the SLP anomaly over the region with the largest response to global warming $\left(45^{\circ}-65^{\circ} \mathrm{N}, 170^{\circ}-125^{\circ} \mathrm{W}\right)$. For four of the HAPPI models, the deepening of the negative SLP anomaly over the northeast Pacific with global warming is significantly different from 0 when there are at least 11 members (Figs. 6a-f). The other models (MIROC5, CESM8.5) do not exhibit any significant change in the strength 
(a) CAM4-2degree

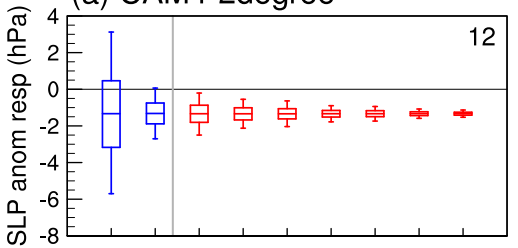

(b) CanAM4

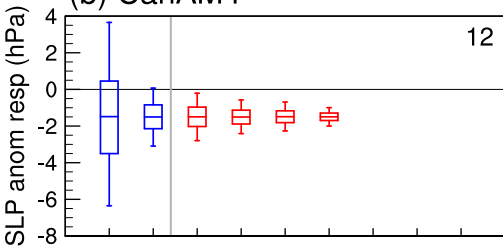

(c) ECHAM6-3-LR

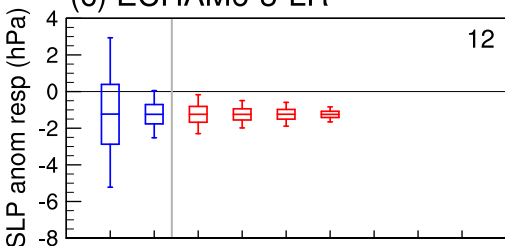

(d) MIROC5

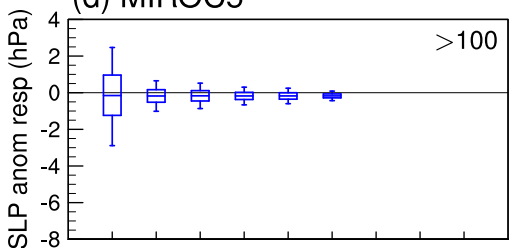

(e) NorESM1-Happi

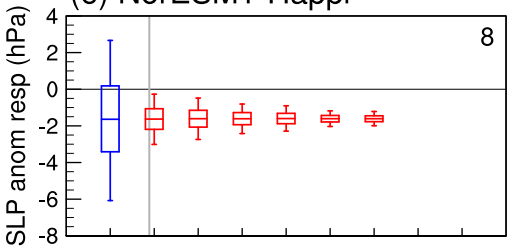

(f) CESM8.5

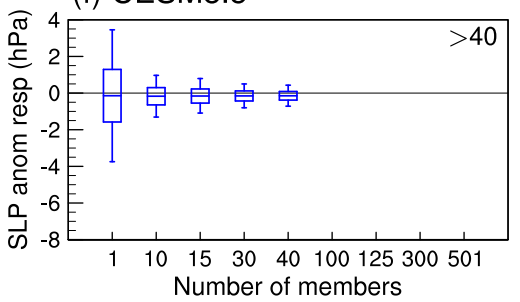

(g) CAM4-2degree

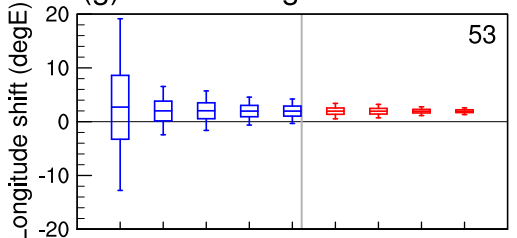

(h) CanAM4

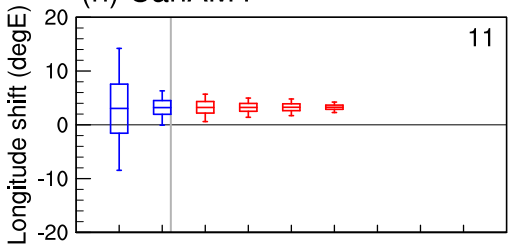

(i) ECHAM6-3-LR

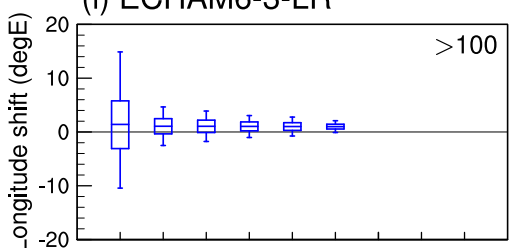

(j) MIROC5

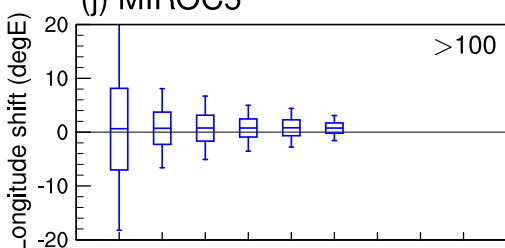

(k) NorESM1-Happi

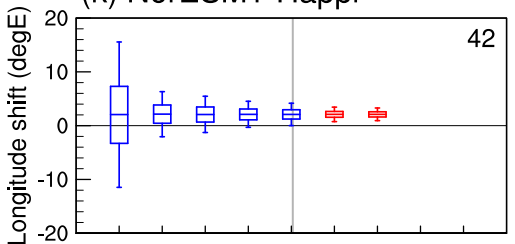

(I) CESM8.5

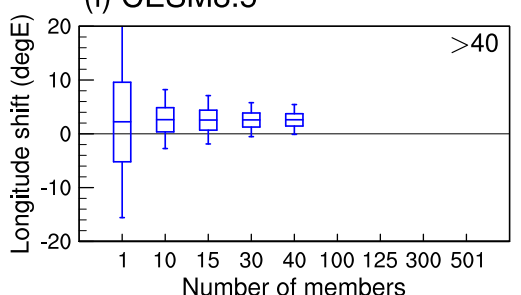

(m) CAM4-2degree

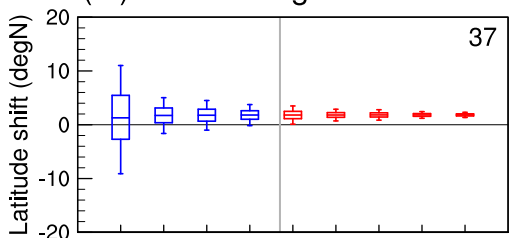

(n) CanAM4

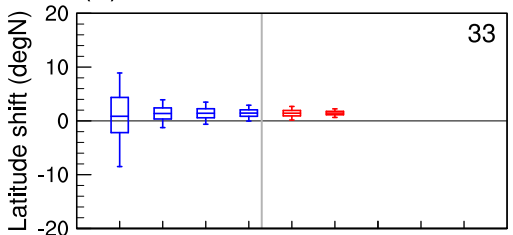

(o) ECHAM6-3-LR

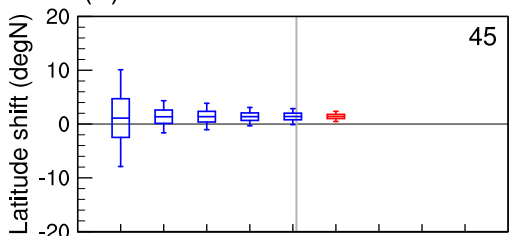

(p) MIROC5

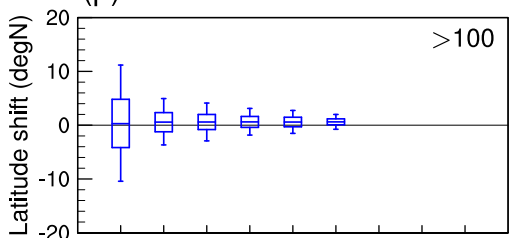

(q) NorESM1-Happi

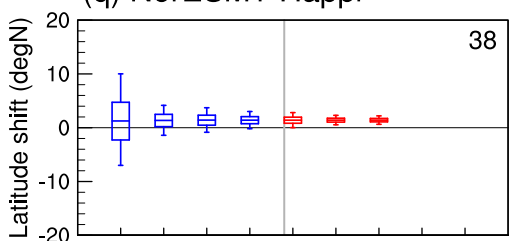

(r) CESM8.5

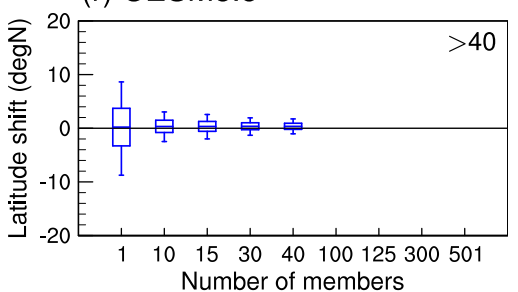

FIG. 6. Detection of robust changes in the North Pacific ENSO teleconnection. Panels show bootstrapped distributions of various features of the teleconnection response to warming as a function of the ensemble size: (left) intensity of ENSO DJF SLP anomaly averaged over the northeast Pacific, and shifts in (center) longitude and (right) latitude of the center of the ENSO DJF SLP anomaly [see Eq. (1) in section 2 for definition] in (a),(g),(m) CAM4-2degree, (b),(h),(n) CanAM4, (c),(i),(o) ECHAM6.3-LR, (d),(j),(p) MIROC5, (e),(k),(q) NorESM1-Happi, and (f),(l),(r) CESM8.5. The boxes show the interquartile range and the whiskers extend to the 5th and 95th percentiles. The vertical gray line and number in the top-right corner show the number of members required for the 5 th-95th percentile range to not encompass zero, considered as a significant deepening or shift of the SLP anomaly. See text for more details. 
(a)

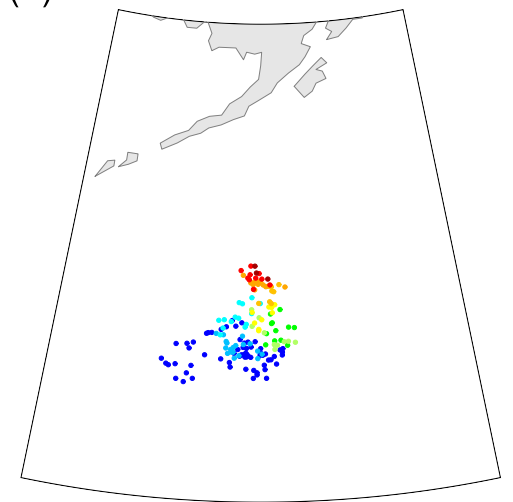

(b)

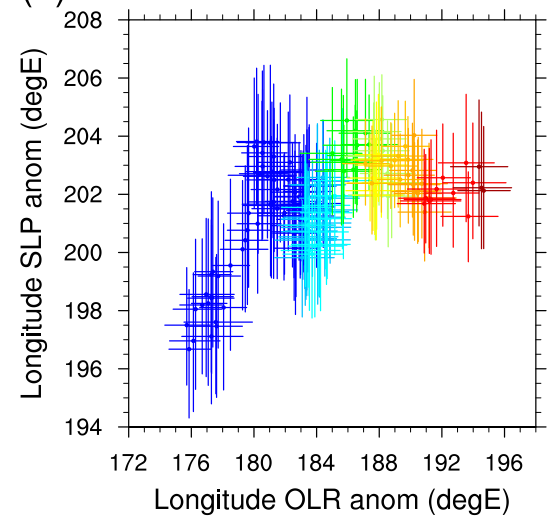

(c)

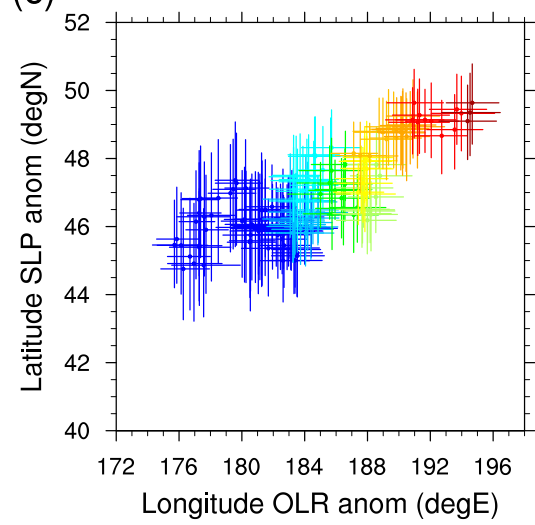

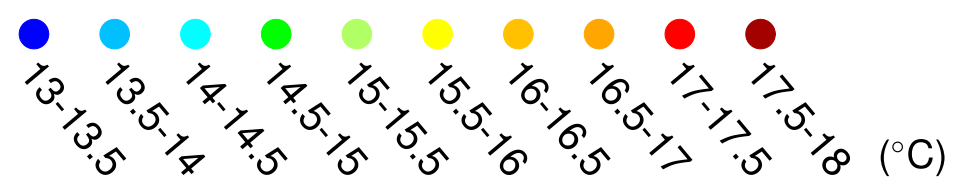

FIG. 7. Shift in the North Pacific ENSO teleconnection in the coupled CESM8.5 simulations. (a) Position of the center of the ensemble-mean ENSO DJF SLP anomaly for the one hundred sixty-two 20-yr periods of the coupled CESM8.5 (1920-2100). (b) Longitude of the ensemble-mean North Pacific center vs longitude of the ensemble-mean equatorial OLR center for the one hundred sixty-two 20-yr periods. (c) As in (b), but for the latitude of the ENSO DJF SLP anomaly center. Every point corresponds to a 20-yr period and is colored according to the value of the ensemble-mean global annual mean temperature for the 20 -yr period considered. Crosshairs in (b) and (c) show the 5th-95th percentile range of the bootstrapped distributions of longitude and latitude.

of the SLP anomaly in the considered region. From Fig. 4, we could already guess that the deepening in these two models is not detectable even for the maximum ensemble size (Figs. 6d,f).

Detecting a significant shift of the ENSO teleconnection in a low warming scenario requires a large number of members, from 11 to more than 100 depending on the model (Figs. 6g-r). Assuming the models exhibit realistic internal variability, such a shift would be difficult to detect in the real world. Only 11 members of CanAM4 are required for the longitudinal shift to be significant, whereas even 100 members of the ECHAM6.3-LR or MIROC5 models are not enough (Figs. 6g-1). The latitudinal shift becomes detectable with 33-45 member ensembles for all HAPPI models except MIROC5 (Figs. 6m-q) and is not detectable in CESM8.5 (Fig. 6r).

For an evolution-with-time perspective, we look at the full period of CESM8.5 from 1920 to 2100. The North Pacific teleconnection center for running 20-yr periods, as defined in section 2, moves overall northeastward with time and increasing global annual mean temperature (Fig. 7a). The shift is not monotonic, which likely reflects the large internal variability of the ENSO teleconnection (Figs. 7b,c). Indeed, taking two other 20-yr periods, sharing the same amount of warming as the HAPPI experiments $\left(+1.2^{\circ} \mathrm{C}\right)$ can produce a westward shift of the teleconnection with warming, in contrast to the eastward shift observed for our chosen periods and the HAPPI experiments. O'Reilly (2018) also noted, using observational and simulated data covering the twentieth century, a nonmonotonic change with time of the ENSO teleconnection but in terms of its strength with periods of strong and weak DJF SLP anomalies in the North Pacific. In our results, there is no stationary relationship between the longitude of the SLP anomaly and the longitude of the OLR anomaly (Fig. 7b), whereas there seems to be a clear relationship between the latitude of the SLP anomaly and the longitude of the OLR anomaly (Fig. 7c): as the OLR anomaly shifts east, the SLP anomaly shifts north.

These results highlight that atmospheric internal variability introduces substantial uncertainty to the response of the ENSO teleconnection, even in the North Pacific where the teleconnection itself is most robust. In the HAPPI runs, the teleconnection pattern arises from the same set of ENSO events in all members, meaning that internal atmospheric variability is the main source of the considerable ensemble spread. In the coupled CESM8.5, the ENSO response is more uncertain and the ENSO events themselves are more diverse, indicating that sampling of ENSO events and an interactive ocean could also be sources of uncertainty. Finally, we note that the level of global warming in this study $\left(+2^{\circ} \mathrm{C}\right.$ relative to preindustrial conditions) is relatively weak; a 
(a) Temp. anom. Present

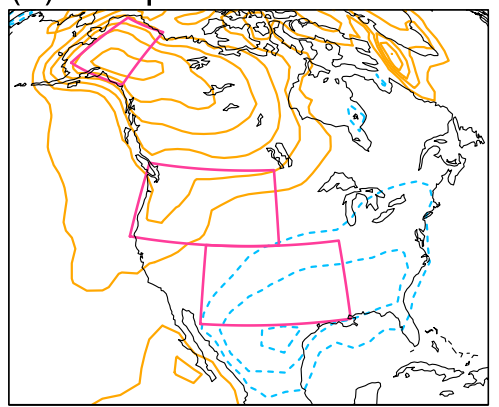

(d) $2^{\circ} \mathrm{C}$-Present

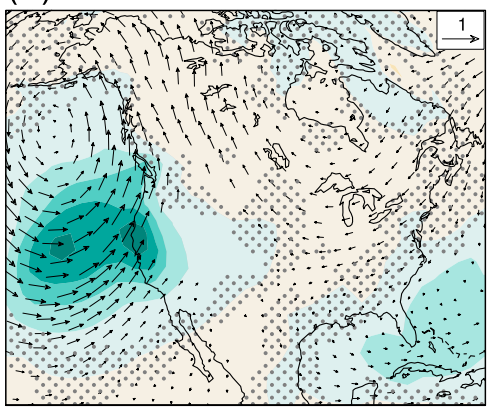

\section{(b) $2^{\circ} \mathrm{C}$-Present}

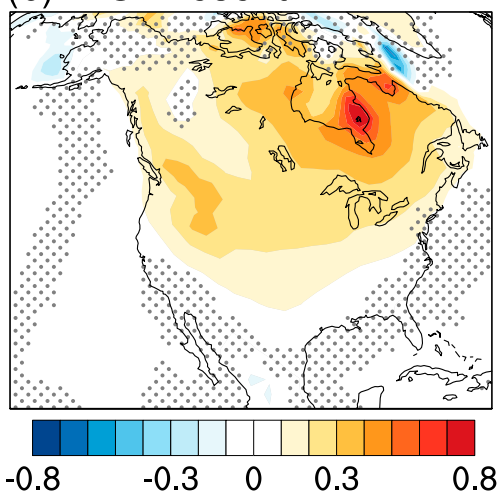

(K)

(e) 0.084 Present

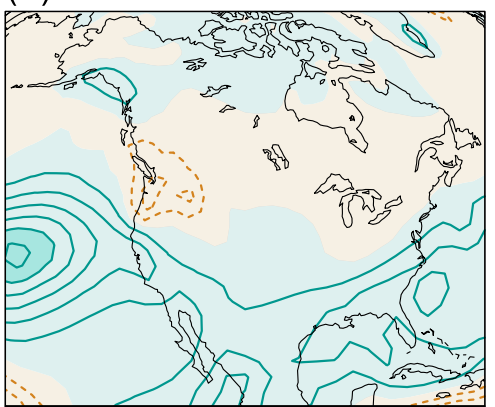

(c) Precip. anom. Present

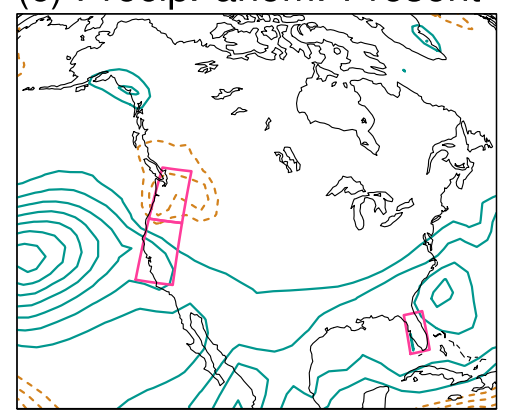

.

(f) (d) $-(e)=2^{\circ} \mathrm{C}-1.084$ Present

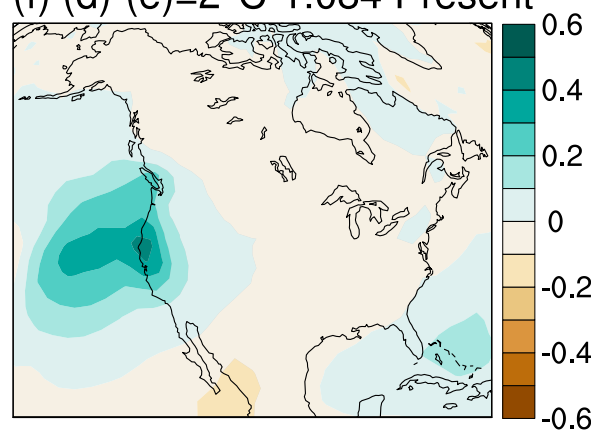

$\left(\mathrm{mm}\right.$ day $^{-1}$ )

FIG. 8. Detection of the robust changes in DJF ENSO impacts over North America. (a) HAPPI ensemble-mean ENSO temperature anomalies for the present-day experiment [interval: $0.4 \mathrm{~K}$; zero-contour omitted; orange solid (blue dashed) lines represent positive (negative) values] and (b) the response to $+2^{\circ} \mathrm{C}$ warming. (c),(d) As in (a) and (b), but for the precipitation anomalies [interval: $0.2 \mathrm{~mm}$ day $^{-1}$; zero-contour omitted; green solid (brown dashed) lines represent positive (negative) values]. Vectors in (d) represent the response of ENSO 850-hPa wind anomalies $\left(\mathrm{m} \mathrm{s}^{-1}\right)$ to warming. (e) ENSO precipitation anomalies that arise from the thermodynamic effect only [8.4\% of present-day anomalies in (c)] [contour interval: $0.02 \mathrm{~mm}^{-1 a y}{ }^{-1}$; zero-contour omitted, solid (dashed) lines represent positive (negative) values]. (f) Difference between (d) and (e), that is, the difference between the $+2^{\circ} \mathrm{C}$ and the predicted [from Eq. (2)] precipitation anomalies. Pink boxes in (a) and (b) show the regions in which the temperature and precipitation anomalies are averaged for Fig. 9. The stippling is present when less than four models out of five agree on the sign of the HAPPI ensemble-mean response.

larger global warming may reduce the number of events required for a robust signal.

\section{North American impacts}

ENSO is an important source of predictability in seasonal climate forecasts over North America (Shukla et al. 2000). The North Pacific center of action is associated with large-scale circulation anomalies that affect temperature and rainfall over the continent (L'Heureux et al. 2015). Given the response of the ENSO teleconnection to global warming in the HAPPI models, we ask how ENSO's impact over North America may be expected to change considering the role of internal variability and being aware that those changes will be more likely to be true only if the equatorial SST zonal gradient weakens with global warming. We only use the HAPPI experiments in this section as they were purposefully designed for impacts assessment under the Paris Agreement targets.

\section{a. Surface temperature impact}

The present-day ENSO impact on near-surface air temperature is relatively well simulated by the HAPPI models, with warm anomalies over Alaska extending southeast over Canada and the United States and cold anomalies over the southern United States (Fig. 8a), in agreement with observations (Fig. S7 and e.g., Ropelewski and Halpert 1986; Livezey et al. 1997) and coupled climate models (Deser et al. 2018; Perry et al. 2020).

The future impacts of ENSO over North America and their robustness against internal variability and model dependency strongly depend on the region considered. Overall, the response of the temperature anomalies to 
the weak global warming is positive over large parts of North America, with at least four models agreeing on the sign of the response. For El Niño, this positive response reinforces the positive temperature anomalies over the northern part of the continent and partially offsets the negative anomalies over the southern part (Figs. 8a,b). Anomalies are opposite for La Niña. In the northwestern United States, El Niño (La Niña) is associated with significantly warmer (colder) than usual conditions for all but one model (see ECHAM6.3-LR, i.e., M3 in Fig. 9b). These ENSO anomalies amplify with global warming, leading to a significantly larger difference between El Niño and La Niña for all models except MIROC5 (M4 in Fig. 9b). In contrast to the northwestern region where the future impacts are quite robust, the future impacts over the southern United States (South Central region in Fig. 9) and Alaska are rather uncertain, because of the weak response and model uncertainty. Over the southern United States, the present-day temperature is significantly colder (warmer) than usual during El Niño (La Niña) (Fig. 9c). The five models show slightly decreased impacts in the future, as inferred from the weak response in Fig. 8b, with El Niño and La Niña becoming significantly more similar in only two models (CAM4-2degree and NorESM1-Happi, i.e., M1 and M5, in Fig. 9c). Over Alaska, the present-day ENSO impacts are very large, with El Niño (La Niña) showing warmer (colder) than usual conditions (Fig. 8a). However, the response to the low warming is very model-dependent and not significant, except for CAM4-2degree, which exhibits the smallest 5th-95th percentile range (i.e., weakest internal variability; Fig. 9a). Over the Great Lakes, the presentday ENSO temperature impacts are very weak and model dependent; despite a positive response to warming in the region (Fig. 8b), only three out of five models show a consistent change in impacts, with El Niño and La Niña becoming more similar (Fig. S8).

\section{b. Impact on precipitation}

The strongest precipitation impacts of ENSO anomalies occur over the eastern North Pacific, the North American west coast, and the southeastern United States (Fig. 8c), in agreement with observations and coupled models (Fig. S7; e.g., Ropelewski and Halpert 1986; Livezey et al. 1997; Jong et al. 2016; Deser et al. 2018; Perry et al. 2020). Along the North American west coast, there is a dipole pattern with positive (negative) anomalies to the south and negative (positive) anomalies to the north during El Niño (La Niña). The precipitation anomalies are consistent across all models except CAM4-2degree (M1 in Fig. 9) in the southwest region (see black boxes in Fig. 9d). The response to warming is increased precipitation along the west coast and Gulf of Mexico (Fig. 8d), leading to a significantly larger difference between El Niño (even wetter) and La Niña (even drier) (Fig. 9d). In contrast, the northern part of the coast sees a response that weakens the ENSO impacts (Fig. 8d), decreasing the difference between El Niño and La Niña, although only two models exhibit significant changes (Fig. 9e). In Florida, El Niño (La Niña) is significantly wetter (drier) than usual in both the presentday and $+2^{\circ} \mathrm{C}$ experiments, with El Niño and La Niña becoming significantly more dissimilar under weak global warming in all HAPPI models (Fig. 9f).

The precipitation response to global warming is driven by both dynamical (atmospheric circulation) and thermodynamical (larger moisture content in the atmosphere with higher temperature) processes. An approximation based on the Clausius-Clapeyron equation gives an increase in saturation vapor pressure (hence precipitation) of about $7 \%$ for every $1 \mathrm{~K}$ of global warming (Held and Soden 2006) under the assumptions that warming is uniform in the lower troposphere and that the relative humidity stays constant. For the $1.2-\mathrm{K}$ warming between the $+2^{\circ} \mathrm{C}$ and present-day experiment, this scaling predicts a precipitation increase of $8.4 \%$. The predicted future precipitation anomalies through thermodynamic effects alone $\mathrm{PR}_{\text {predicted }}^{\prime}$ would then be

$$
\mathrm{PR}_{\text {predicted }}^{\prime}=\mathrm{PR}_{\text {present }}^{\prime}+0.084 \mathrm{PR}_{\text {present }}^{\prime},
$$

where $\mathrm{PR}_{\text {present }}^{\prime}$ is the present-day multi-HAPPI model mean precipitation anomaly.

The thermodynamic effect accounts for only a slight strengthening $\left(<0.08 \mathrm{~mm} \mathrm{day}^{-1}\right.$ in absolute values) of the ENSO precipitation anomalies (Fig. 8e) and thus does not explain the total response to the imposed warming (Fig. 8d). Dynamics must play a role. Over Mexico, the negative dynamical effect opposes the positive thermodynamic effect, leading to a slight negative response in this low warming scenario (cf. Figs. 8e,f to Fig. 8d). However, over the North Atlantic, North Pacific, and North American west coast, dynamics reinforces the positive thermodynamic effect (cf. Figs. 8e,f to Fig. 8d). In particular, over the North Pacific, the low-level wind response to warming features a cyclonic anomaly transporting the moisture along the North American west coast where it precipitates probably for orographical reasons (the presence of the Sierra Nevada, Coast Ranges, and Cascade Range) (Li et al. 2018).

\section{Discussion}

The HAPPI experimental setup as well as the HAPPI models themselves and their ability to accurately represent 
(a) Alaska
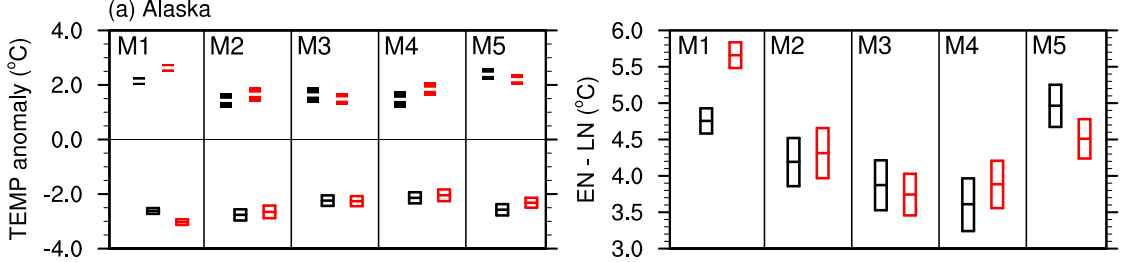

(b) West
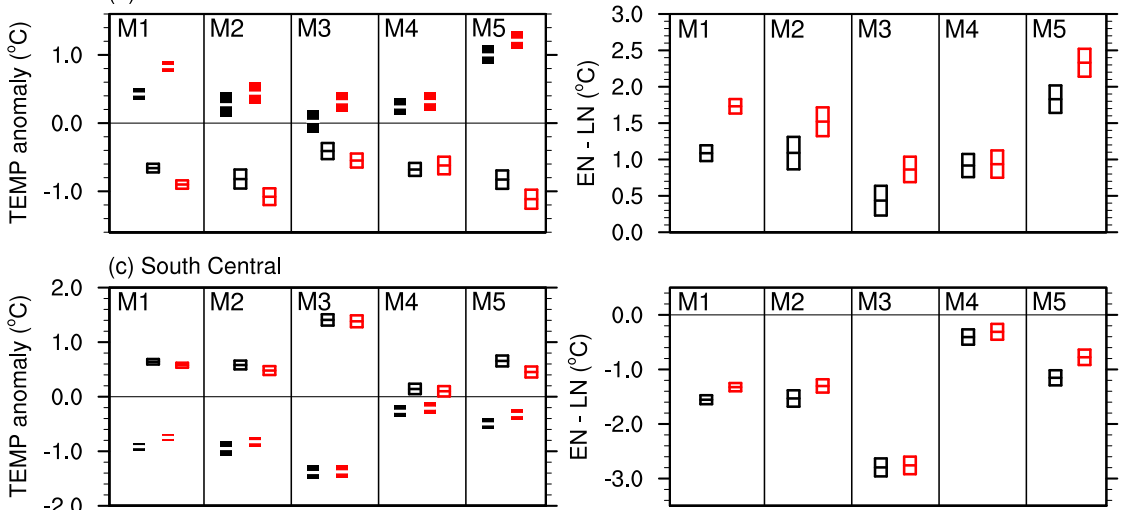

(d) South-West
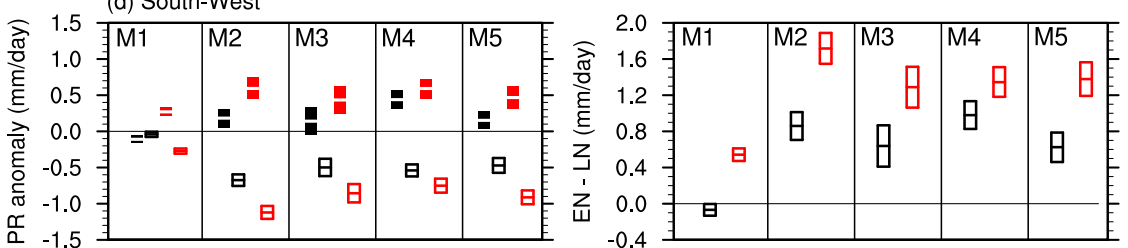

(e) North-West
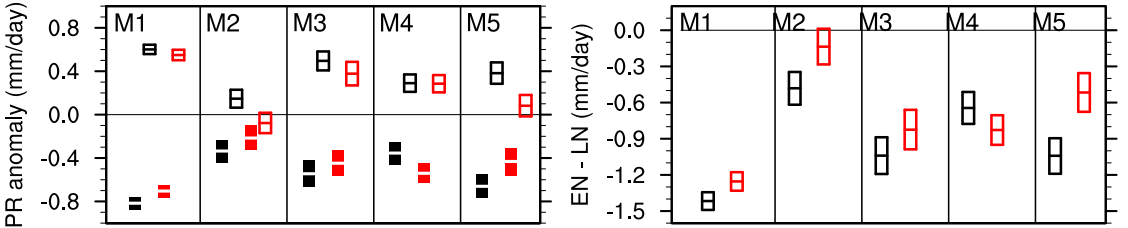

(f) Florida
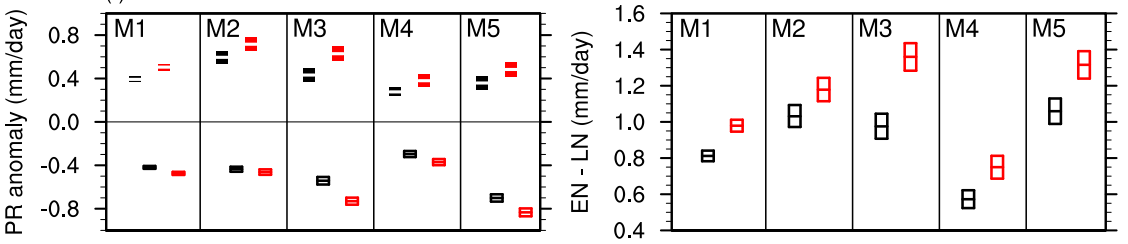

FIG. 9. Regional responses of DJF ENSO impacts to global warming in the five HAPPI models (M1-M5) only including the five common ENSO events. (left) Near-surface temperature anomaly over (a) Alaska $\left(160^{\circ}-140^{\circ} \mathrm{W}, 60^{\circ}-70^{\circ} \mathrm{N}\right)$, (b) western North America $\left(125^{\circ}-95^{\circ} \mathrm{W}, 40^{\circ}-50^{\circ} \mathrm{N}\right)$, and (c) southern North America (South Central, $112^{\circ}-90^{\circ} \mathrm{W}, 30^{\circ}-$ $40^{\circ} \mathrm{N}$ ) for El Niño (solid boxes) and La Niña (empty boxes) for the present-day (black boxes) and $+2^{\circ} \mathrm{C}$ experiments (red boxes). The line in the middle of the box shows the mean of the bootstrapped distribution with the box's lower and upper limits being the 5th and 95th percentiles. (right) Differences between El Niño and La Niña regional averages of the left panels in (a)-(c). Black boxes refer to the present-day experiment and red boxes to the $+2^{\circ} \mathrm{C}$ experiment. (d)-(f) As in (a)-(c), but for the precipitation anomalies over the southern region of the West Coast $\left(124^{\circ}-118^{\circ} \mathrm{W}, 35^{\circ}-43^{\circ} \mathrm{N}\right)$ in $(\mathrm{d})$, the northern region of the West Coast $\left(124^{\circ}-118^{\circ} \mathrm{W}, 43^{\circ}-50^{\circ} \mathrm{N}\right)$ in $(\mathrm{e})$, and Florida $\left(83^{\circ}-80^{\circ} \mathrm{W}, 25^{\circ}-30^{\circ} \mathrm{N}\right)$ in (f). Within each panel, each column shows one model with $\mathrm{M} 1=\mathrm{CAM} 4-2$ degree, $\mathrm{M} 2=$ CanAM4, M3 = ECHAM6.3-LR, M4 = MIROC5, and M5 = NorESM1-Happi. 
atmospheric processes are factors that can influence the interpretation of the present study's results, which features an important role for internal variability in shaping future changes of the ENSO teleconnection.

As the response of the ENSO teleconnection to global warming is tightly linked to the response of convection in the tropics, any uncertainty in the latter must be considered in interpreting the results of this study. By using the CMIP5 multimodel mean SST response, the HAPPI setup assumes that the zonal SST gradient in the equatorial Pacific will weaken in the future, favoring an eastward migration of convection. However, recent studies have argued that the real world may not be trending toward a warmer eastern equatorial Pacific in the same way that the models are (L'Heureux et al. 2013; Sohn et al. 2013; Sandeep et al. 2014; Coats and Karnauskas 2017; Bayr et al. 2019; Johnson et al. 2019; Seager et al. 2019). If this is correct, the ENSO teleconnection may not shift eastward with global warming, although even uniform tropical warming does seem to create some eastward shift (Zhou et al. 2014). Whether models are indeed incorrect in this regard is an active topic of research. In addition to shifting, the convection anomalies associated with ENSO are also expected to strengthen with global warming (Kug et al. 2010; Seager et al. 2012; Johnson et al. 2019), which can then influence the ENSO teleconnection through the SLP anomaly strength, for example. Idealized simulations with prescribed equatorial convection could be useful in investigating the relative roles of the position and strength of the convection anomalies in the North Pacific ENSO teleconnection.

The results from the uncoupled HAPPI models are in relatively good agreement with those of the coupled CESM1 model and in qualitative agreement with most of the CMIP5 models in a stronger warming scenario (Christensen et al. 2013). However, the similarities between HAPPI, CESM8.5, and CMIP5 are corroborated by Deser et al.'s (2017) study, which does not show large differences in the present-day ENSO teleconnection in pacemaker versus Tropical Ocean and the Global Atmosphere (TOGA) simulations. We do not have the appropriate experiments to test quantitatively whether this is true for the response to warming, but the similarity between HAPPI and CESM8.5 suggests the results would be similar in coupled frameworks. This is despite the fact that the HAPPI framework does not represent the two-way atmosphere-ocean interactions, including changes in upwelling, thermocline depth, and surface heat and radiative fluxes that can modify the amplitude, pattern, and variability of ENSO (Collins et al. 2010). It would be worthwhile confirming these results with a wider range of coupled large ensembles where the ocean can react to atmospheric changes (Garfinkel et al. 2018), the nature of ENSO can also change under warming, and the simulations can capture a richer spectrum of ENSO events. In addition, there may be other sources of variability that are missing from this HAPPI ensemble that may further enhance the uncertainty in projected changes. For example, the Pacific decadal oscillation (PDO) does not play an important role over the short HAPPI record, but it could further increase the sampling uncertainty if it were present, or if the PDO and/or its modulation of ENSO were to change with global warming too (Zhang and Delworth 2016; Mantua et al. 1997; Zhang et al. 1997; Wang and An 2001; Jia and Ge 2017; Wills et al. 2018, and references therein).

ENSO is known to modulate the NAO with El Niño (La Niña) favoring the negative (positive) phase of the NAO (e.g., Fraedrich and Müller 1992). One of the pathways connecting ENSO to the North Atlantic is through the stratosphere (Jiménez-Esteve and Domeisen 2018). However, the HAPPI models do not resolve the stratosphere very well and thus may not adequately represent troposphere-stratosphere interactions, which may impact the response to warming of the ENSO influence onto the NAO.

Our overall aim was to assess the uncertainty due to atmospheric internal variability in the response of the extratropical ENSO teleconnection to warming by taking advantage of a very large ensemble of simulations. There are important caveats concerning experiment design and model uncertainty, as discussed above. However, the results are robust and emphasize the importance of sampling the internal variability thoroughly in order to accurately determine the forced response under a low warming scenario, as would be expected in the coming decades if the Paris Agreement target is met.

\section{Conclusions}

The wintertime atmospheric teleconnection of ENSO in the North Pacific shifts northeastward by a few degrees with $+2^{\circ} \mathrm{C}$ of global warming in the HAPPI large ensemble. The shift is tightly linked to changes in the position and intensity of the forcing by convection in the equatorial region, as represented by OLR: the farther east and the stronger (more negative) the tropical OLR anomaly, the farther northeast the extratropical SLP anomaly. The displacement relationship has been noted in other climate models, with relevance for issues such as impacts of cold tongue SST biases, which are common to many models (e.g., Bayr et al. 2019). Detecting the northeastward shift in the SLP anomaly requires at least 
10-15 HAPPI ensemble members of 1 decade each, or equivalently 50-75 ENSO events, in both the present and future climates. Some models (MIROC5, and to a lesser extent, ECHAM6.3-LR) show a tendency toward a northeastward shift, but the shift is not significant even with 100 ensemble members (500 ENSO events). Even more events may be needed if one includes other sources of uncertainty not considered in our experimental setup, such as changes in ENSO itself (Berner et al. 2020). CESM8.5, which includes eventual changes in ENSO under a weak warming, also shows a tendency toward a northeastward shift that is not significant with 40 members. However, fewer members would be required if the signal were greater (e.g., under a higher global warming scenario). The results highlight that, for low warming scenarios, changes in the atmospheric ENSO teleconnection are highly uncertain due to internal atmospheric variability. This large uncertainty may explain why past studies using smaller ensemble sizes have found different ENSO responses to climate change (e.g., Meehl and Teng 2007; Schneider et al. 2009; Christensen et al. 2013). It also suggests that the observational period (1920-2013), which includes 32 ENSO events (Deser et al. 2017, 2018), is too short to use as a baseline for assessing changes in the ENSO teleconnection under Paris Agreement warming targets. For North American impacts, precipitation changes with global warming are relatively robust compared to temperature changes and are dominated by the changes in the atmospheric circulation rather than the thermodynamic effect.

Acknowledgments. The authors thank the three reviewers whose comments improved the manuscript. This work was funded by the Norwegian Research Council projects 255027 DynAMiTe, 231716 jetSTREAM, and 261821 HappiEVA. We are thankful to UNINETT Sigma2 AS for managing the national infrastructure for computational science in Norway (project NS9082K), the European Centre for Medium-Range Weather Forecasts for providing the ERA-Interim reanalyses, the HAPPI project for producing such a very large ensemble of simulations, and the National Center for Atmospheric Research for providing the large ensemble of the Community Earth System Model.

\section{REFERENCES}

Atwood, A. R., D. S. Battisti, A. T. Wittenberg, W. H. G. Roberts, and D. J. Vimont, 2017: Characterizing unforced multidecadal variability of ENSO: A case study with the GFDL CM2.1 coupled GCM. Climate Dyn., 49, 2845-2862, https:// doi.org/10.1007/s00382-016-3477-9.

Bayr, T., D. I. V. Domeisen, and C. Wengel, 2019: The effect of the equatorial Pacific cold SST bias on simulated ENSO tele- connections to the North Pacific and California. Climate Dyn., 53, 3771-3789, https://doi.org/10.1007/s00382-019-04746-9.

Berner, J., H. M. Christensen, and P. D. Sardeshmukh, 2020: Does ENSO regularity increase in a warming climate? J. Climate, 33, 1247-1259, https://doi.org/10.1175/JCLI-D-19-0545.1.

Bjerknes, J., 1969: Atmospheric teleconnections from the equatorial Pacific. Mon. Wea. Rev., 97, 163-172, https://doi.org/ 10.1175/1520-0493(1969)097<0163:ATFTEP > 2.3.CO;2.

Brands, S., 2017: Which ENSO teleconnections are robust to internal atmospheric variability? Geophys. Res. Lett., 44, 14831493, https://doi.org/10.1002/2016GL071529.

Brönnimann, S., 2007: Impact of El Niño-Southern Oscillation on European climate. Rev. Geophys., 45, RG3003, https://doi.org/ 10.1029/2006RG000199.

Cai, W., P. van Rensch, T. Cowan, and H. H. Hendon, 2011: Teleconnection pathways of ENSO and the IOD and the mechanisms for impacts on Australian rainfall. J. Climate, 24, 3910-3923, https://doi.org/10.1175/2011JCLI4129.1.

- , and Coauthors, 2015: ENSO and greenhouse warming. Nat. Climate Change, 5, 849-859, https://doi.org/10.1038/nclimate2743.

Chen, M., and A. Kumar, 2015: Influence of ENSO SSTs on the spread of the probability density function for precipitation and land surface temperature. Climate Dyn., 45, 965-974, https:// doi.org/10.1007/s00382-014-2336-9.

Christensen, J. H., and Coauthors, 2013: Climate phenomena and their relevance for future regional climate change. Climate Change 2013: The Physical Science Basis, T. F. Stocker et al., Eds., Cambridge University Press, 1217-1308.

Coats, S., and K. B. Karnauskas, 2017: Are simulated and observed twentieth century tropical Pacific sea surface temperature trends significant relative to internal variability? Geophys. Res. Lett., 44, 9928-9937, https://doi.org/10.1002/2017GL074622.

Collins, M., and Coauthors, 2010: The impact of global warming on the tropical Pacific Ocean and El Niño. Nat. Geosci., 3, 391397, https://doi.org/10.1038/ngeo868.

Dee, D. P., and Coauthors, 2011: The ERA-Interim reanalysis: Configuration and performance of the data assimilation system. Quart. J. Roy. Meteor. Soc., 137, 553-597, https://doi.org/ 10.1002/qj.828.

Deser, C., I. R. Simpson, K. A. McKinnon, and A. S. Phillips, 2017: The Northern Hemisphere extratropical atmospheric circulation response to ENSO: How well do we know it and how do we evaluate models accordingly? J. Climate, 30, 5059-5082, https://doi.org/10.1175/JCLI-D-16-0844.1.

,-- A. S. Phillips, and K. A. McKinnon, 2018: How well do we know ENSO's climate impacts over North America, and how do we evaluate models accordingly? J. Climate, 31, 49915014, https://doi.org/10.1175/JCLI-D-17-0783.1.

Diaz, H. F., M. P. Hoerling, and J. K. Eischeid, 2001: ENSO variability, teleconnections and climate change. Int. J. Climatol., 21, 1845-1862, https://doi.org/10.1002/joc.631.

Drouard, M., and C. Cassou, 2019: A modeling and process-oriented study to investigate the projected change of ENSO-forced wintertime teleconnectivity in a warmer world. J. Climate, $\mathbf{3 2}$, 8047-8068, https://doi.org/10.1175/JCLI-D-18-0803.1.

Fasullo, J., B. L. Otto-Bliesner, and S. Stevenson, 2018: ENSO's changing influence on temperature, precipitation, and wildfire in a warming climate. Geophys. Res. Lett., 45, 9216-9225, https://doi.org/10.1029/2018GL079022.

Feng, J., W. Chen, and Y. Li, 2017: Asymmetry of the winter extratropical teleconnections in the Northern Hemisphere associated with two types of ENSO. Climate Dyn., 48, 2135-2151, https://doi.org/10.1007/s00382-016-3196-2. 
— T. Lian, J. Ying, J. Li, and G. Li, 2020: Do CMIP5 models show El Niño diversity? J. Climate, 33, 1619-1641, https:// doi.org/10.1175/JCLI-D-18-0854.1.

Fraedrich, K., 1994: An ENSO impact on Europe? Tellus, 46A, 541-552, https://doi.org/10.3402/tellusa.v46i4.15643.

__ and K. Müller, 1992: Climate anomalies in Europe associated with ENSO extremes. Int. J. Climatol., 12, 25-31, https:// doi.org/10.1002/joc.3370120104.

Garfinkel, C. I., I. Weinberger, I. P. White, L. D. Oman, V. Aquila, and Y.-K. Lim, 2018: The salience of nonlinearities in the boreal winter response to ENSO: North Pacific and North America. Climate Dyn., 52, 4429-4446, https://doi.org/10.1007/ s00382-018-4386-x.

Grimm, A. M., and R. G. Tedeschi, 2009: ENSO and extreme rainfall events in South America. J. Climate, 22, 1589-1609, https://doi.org/10.1175/2008JCLI2429.1.

Held, I. M., and B. J. Soden, 2006: Robust responses of the hydrological cycle to global warming. J. Climate, 19, 5686-5699, https://doi.org/10.1175/JCLI3990.1.

Herceg Bulić, I., and Č. Branković, 2007: ENSO forcing of the Northern Hemisphere climate in a large ensemble of model simulations based on a very long SST record. Climate Dyn., 28, 231-254, https://doi.org/10.1007/s00382006-0181-1.

,$- \ldots$, and F. Kucharski, 2012: Winter ENSO teleconnections in a warmer climate. Climate Dyn., 38, 1593-1613, https:// doi.org/10.1007/s00382-010-0987-8.

Hoerling, M. P., and M. Ting, 1994: Organization of extratropical transients during El Niño. J. Climate, 7, 745-766, https://doi.org/ 10.1175/1520-0442(1994)007<0745:OOETDE > 2.0.CO;2.

_ - A. Kumar, and M. Zhong, 1997: El Niño, La Niña, and the nonlinearity of their teleconnections. J. Climate, 10, 1769-1786, https://doi.org/10.1175/1520-0442(1997)010<1769:ENOLNA> 2.0.CO;2.

Horel, J. D., and J. M. Wallace, 1981: Planetary-scale atmospheric phenomena associated with the Southern Oscillation. Mon. Wea. Rev., 109, 813-829, https://doi.org/10.1175/1520-0493(1981) 109<0813:PSAPAW > 2.0.CO;2.

Huang, R., and Y. Wu, 1989: The influence of ENSO on the summer climate change in China and its mechanism. Adv. Atmos. Sci., 6, 21-32, https://doi.org/10.1007/BF02656915.

Jia, X., and J. Ge, 2017: Modulation of the PDO to the relationship between moderate ENSO events and the winter climate over North America. Int. J. Climatol., 37, 4275-4287, https:// doi.org/10.1002/joc.5083.

Jiménez-Esteve, B., and D. I. V. Domeisen, 2018: The tropospheric pathway of the ENSO-North Atlantic teleconnection. J. Climate, 31, 4563-4584, https://doi.org/10.1175/JCLI-D17-0716.1.

—_, and _ 2019: Nonlinearity in the North Pacific atmospheric response to a linear ENSO forcing. Geophys. Res. Lett., 46, 2271-2281, https://doi.org/10.1029/2018GL081226.

Johnson, N. C., M. L. L'Heureux, C.-H. Chang, and Z.-Z. Hu, 2019: On the delayed coupling between ocean and atmosphere in recent weak El Niño episodes. Geophys. Res. Lett., 46, 11 41611 425, https://doi.org/10.1029/2019GL084021.

Jong, B.-T., M. Ting, and R. Seager, 2016: El Niño's impact on California precipitation: Seasonality, regionality, and El Niño intensity. Quart. J. Roy. Meteor. Soc., 11, 054021, https:// doi.org/10.1088/1748-9326/11/5/054021.

Kay, J. E., and Coauthors, 2015: The Community Earth System Model (CESM) large ensemble project: A community resource for studying climate change in the presence of internal climate variability. Bull. Amer. Meteor. Soc., 96, 1333-1349, https://doi.org/10.1175/BAMS-D-13-00255.1.

Kug, J.-S., S.-I. An, Y.-G. Ham, and I.-S. Kang, 2010: Changes in El Niño and La Niña teleconnections over North PacificAmerica in the global warming simulations. Theor. Appl. Climatol., 100, 275-282, https://doi.org/10.1007/s00704-0090183-0.

L'Heureux, M. L., S. Lee, and B. Lyon, 2013: Recent multidecadal strengthening of the Walker circulation across the tropical Pacific. Nat. Climate Change, 3, 571-576, https://doi.org/ 10.1038/nclimate1840.

_, M. K. Tippett, and A. G. Barnston, 2015: Characterizing ENSO coupled variability and its impact on North American seasonal precipitation and temperature. J. Climate, 28, 42314245, https://doi.org/10.1175/JCLI-D-14-00508.1.

Li, C., and Coauthors, 2018: Midlatitude atmospheric circulation responses under 1.5 and $2.0^{\circ} \mathrm{C}$ warming and implications for regional impacts. Earth Syst. Dyn., 9, 359-382, https://doi.org/ 10.5194/esd-9-359-2018.

Liu, Z., S. Vavrus, F. He, N. Wen, and Y. Zhong, 2005: Rethinking tropical ocean response to global warming: The enhanced equatorial warming. J. Climate, 18, 4684-4700, https://doi.org/ 10.1175/JCLI3579.1.

Livezey, R. E., M. Masutani, A. Leetmaa, H. Rui, M. Ji, and A. Kumar, 1997: Teleconnective response of the Pacific-North American region atmosphere to large central equatorial Pacific SST anomalies. J. Climate, 10, 1787-1820, https://doi.org/10.1175/ 1520-0442(1997)010<1787:TROTPN>2.0.CO;2.

Mantua, N. J., S. R. Hare, Y. Zhang, J. M. Wallace, and R. C. Francis, 1997: A Pacific interdecadal climate oscillation with impacts on salmon production. Bull. Amer. Meteor. Soc., 78 , 1069-1079, https://doi.org/10.1175/1520-0477(1997)078<1069: APICOW $>2.0 . C O ; 2$.

Meehl, G. A., and H. Teng, 2007: Multi-model changes in El Niño teleconnections over North America in a future warmer climate. Climate Dyn. 29, 779-790, https://doi.org/10.1007/ S00382-007-0268-3.

Mitchell, D., R. James, P. M. Forster, R. A. Betts, H. Shiogama, and M. Allen, 2016: Realizing the impacts of a $1.5^{\circ} \mathrm{C}$ warmer world. Nat. Climate Change, 6, 735-737, https://doi.org/10.1038/ nclimate3055.

- and Coauthors, 2017: Half a degree additional warming, prognosis and projected impacts (HAPPI): Background and experimental design. Geosci. Model Dev., 10, 571-583, https:// doi.org/10.5194/gmd-10-571-2017.

Müller, W. A., and E. Roeckner, 2006: ENSO impact on midlatitude circulation patterns in future climate change projections. Geophys. Res. Lett., 33, L05711, https://doi.org/10.1029/ 2005 GL025032.

——, and — 2008: ENSO teleconnections in projections of future climate in ECHAM5/MPI-OM. Climate Dyn., 31, 533-549, https://doi.org/10.1007/s00382-007-0357-3.

Okumura, Y. M., and C. Deser, 2010: Asymmetry in the duration of El Niño and La Niña. J. Climate, 23, 5826-5843, https://doi.org/ 10.1175/2010JCLI3592.1.

Olonscheck, D., and D. Notz, 2017: Consistently estimating internal climate variability from climate model simulations. J. Climate, 30, 9555-9573, https://doi.org/10.1175/JCLI-D-16-0428.1.

O'Reilly, C., 2018: Interdecadal variability of the ENSO teleconnection to the wintertime North Pacific. Climate Dyn., 51, 3333-3350, https://doi.org/10.1007/s00382-018-4081-y.

Perry, S. J., S. McGregor, A. Sen Gupta, M. H. England, and N. Maher, 2020: Projected late 21st century changes to the 
regional impacts of the El Niño-Southern Oscillation. Climate Dyn., 54, 395-412, https://doi.org/10.1007/s00382-019-05006-6.

Plisnier, P. D., S. Serneels, and E. F. Lambin, 2000: Impact of ENSO on East African ecosystems: A multivariate analysis based on climate and remote sensing data. Global Ecol. Biogeogr., 9, 481-497, https://doi.org/10.1046/j.1365-2699.2000.00208.x.

Ropelewski, C. F., and M. S. Halpert, 1986: North American precipitation and temperature patterns associated with the El Niño/Southern Oscillation (ENSO). Mon. Wea. Rev., 114, 2352-2362, https://doi.org/10.1175/1520-0493(1986)114<2352: NAPATP $>2.0 . \mathrm{CO} ; 2$.

__ and —_, 1987: Global and regional scale precipitation patterns associated with the El Niño/Southern Oscillation. Mon. Wea. Rev., 115, 1606-1626, https://doi.org/10.1175/ 1520-0493(1987)115<1606:GARSPP > 2.0.CO;2.

Sandeep, S., F. Stordal, P. D. Sardeshmukh, and G. P. Compo, 2014: Pacific Walker circulation variability in coupled and uncoupled climate models. Climate Dyn., 43, 103-117, https:// doi.org/10.1007/s00382-014-2135-3.

Schneider, E. K., M. J. Fennessy, and J. L. Kinter III, 2009: A statistical-dynamical estimate of winter ENSO teleconnections in a future climate. J. Climate, 22, 6624-6638, https://doi.org/ 10.1175/2009JCLI3147.1.

Seager, R., N. Naik, and L. Vogel, 2012: Does global warming cause intensified interannual hydroclimate variability? J. Climate, 25, 3355-3372, https://doi.org/10.1175/JCLI-D-11-00363.1.

_- M. Cane, N. Henderson, D.-E. Lee, R. Abernathey, and H. Zhang, 2019: Strengthening tropical Pacific zonal sea surface temperature gradient consistent with rising greenhouse gases. Nat. Climate Change, 9, 517-522, https://doi.org/10.1038/ s41558-019-0505-x.

Shukla, J., and Coauthors, 2000: Dynamical seasonal prediction. Bull. Amer. Meteor. Soc., 81, 2593-2606, https://doi.org/ 10.1175/1520-0477(2000)081<2593:DSP $>2.3 . C O ; 2$.

Sohn, B. J., S.-W. Yeh, J. Schmetz, and H.-J. Song, 2013: Observational evidences of Walker circulation change over the last 30 years contrasting with GCM results. Climate Dyn., 40, 1721-1732, https://doi.org/10.1007/s00382-012-1484-z.

Stevenson, S., B. Fox-Kemper, M. Jochum, R. Neale, C. Deser, and G. Meehl, 2012: Will there be a significant change to El Niño in the twenty-first century? J. Climate, 25, 2129-2145, https:// doi.org/10.1175/JCLI-D-11-00252.1.

2012: Significant changes to ENSO strength and impacts in the twenty-first century: Results from CMIP5. Geophys. Res. Lett., 39, L17703, https://doi.org/10.1029/2012GL052759.

Toniazzo, T., and A. A. Scaife, 2006: The influence of ENSO on winter North Atlantic climate. Geophys. Res. Lett., 33, L24704, https://doi.org/10.1029/2006GL027881.

UN-FCCC, 2015: Adoption of the Paris Agreement, Conference of the Parties, 2015. United Nations Framework Convention on
Climate Change, https://unfccc.int/resource/docs/2015/cop21/ eng/109r01.pdf.

Vecchi, G. A., and B. J. Soden, 2007: Global warming and the weakening of the tropical circulation. J. Climate, 20, 43164340, https://doi.org/10.1175/JCLI4258.1.

$\longrightarrow,-$ A. T. Wittenberg, I. M. Held, A. Leetmaa, and M. J. Harrison, 2006: Weakening of tropical Pacific atmospheric circulation due to anthropogenic forcing. Nature, 441, 73-76, https://doi.org/10.1038/nature04744.

Wallace, J. M., and D. S. Gutzler, 1981: Teleconnections in the geopotential height field during the Northern Hemisphere. Mon. Wea. Rev., 109, 784-812, https://doi.org/10.1175/15200493(1981) $109<0784$ :TITGHF $>2.0$. CO 2 .

Wang, B., and S.-I. An, 2001: Why the properties of El Niño changed during the late 1970s. Geophys. Res. Lett., 28, 37093712, https://doi.org/10.1029/2001GL012862.

Wills, R. C., T. Schneider, J. M. Wallace, D. S. Battisti, and D. L. Hartmann, 2018: Disentangling global warming, multidecadal variability, and El Niño in Pacific temperatures. Geophys. Res. Lett., 45, 2487-2496, https://doi.org/10.1002/2017GL076327.

Zhang, L., and T. L. Delworth, 2016: Simulated response of the Pacific decadal oscillation to climate change. J. Climate, 29, 5999-6018, https://doi.org/10.1175/JCLI-D-15-0690.1.

Zhang, T., X. Shao, and S. Li, 2017: Impacts of atmospheric processes on ENSO asymmetry: A comparison between CESM1 and CCSM4. J. Climate, 30, 9743-9762, https://doi.org/10.1175/ JCLI-D-17-0360.1.

Zhang, W., Z. Wang, M. F. Stuecker, A. G. Turner, F.-F. Jin, and X. Geng, 2019: Impact of ENSO longitudinal position on teleconnections to the NAO. Climate Dyn., 52, 257-274, https:// doi.org/10.1007/s00382-018-4135-1.

Zhang, Y., J. M. Wallace, and D. S. Battisti, 1997: ENSO-like interdecadal variability: 1990-93. J. Climate, 10, 1004-1020, https://doi.org/10.1175/1520-0442(1997)010<1004:ELIV> 2.0.CO;2.

Zheng, X.-T., S.-P. Xie, L.-H. Lv, and Z.-Q. Zhou, 2016: Intermodel uncertainty in ENSO amplitude change tied to Pacific Ocean warming pattern. J. Climate, 29, 7265-7279, https://doi.org/10.1175/JCLI-D-16-0039.1.

, C. Hui, and S.-W. Yeh, 2018: Response of ENSO amplitude to global warming in CESM large ensemble: Uncertainty due to internal variability. Climate Dyn., 50, 4019-4035, https:// doi.org/10.1007/s00382-017-3859-7.

Zhou, Z.-Q., S.-P. Xie, X.-T. Zheng, Q. Liu, and H. Wang, 2014: Global warming-induced changes in El Niño teleconnections over the North Pacific and North America. J. Climate, 27, 9050-9064, https://doi.org/10.1175/JCLI-D-14-00254.1.

Zhu, X., and Z. Liu, 2009: Tropical SST response to global warming in the twentieth century. J. Climate, 22, 1305-1312, https:// doi.org/10.1175/2008JCLI2164.1. 